\title{
Comparing offshore and onshore wind development considering acceptance costs
}

\author{
Hevia Koch, Pablo Alejandro; Klinge Jacobsen, Henrik
}

Published in:

Energy Policy

Link to article, DOI:

10.1016/j.enpol.2018.10.019

Publication date:

2019

Document Version

Peer reviewed version

Link back to DTU Orbit

Citation (APA):

Hevia Koch, P. A., \& Klinge Jacobsen, H. (2019). Comparing offshore and onshore wind development considering acceptance costs. Energy Policy, 125, 9-19. https://doi.org/10.1016/j.enpol.2018.10.019

\section{General rights}

Copyright and moral rights for the publications made accessible in the public portal are retained by the authors and/or other copyright owners and it is a condition of accessing publications that users recognise and abide by the legal requirements associated with these rights.

- Users may download and print one copy of any publication from the public portal for the purpose of private study or research.

- You may not further distribute the material or use it for any profit-making activity or commercial gain

- You may freely distribute the URL identifying the publication in the public portal

If you believe that this document breaches copyright please contact us providing details, and we will remove access to the work immediately and investigate your claim 


\title{
Comparing offshore and onshore wind development considering acceptance costs
}

\author{
Pablo Hevia-Koch \& Henrik Klinge Jacobsen*
}

\begin{abstract}
Cost efficient deployment of wind energy is in focus for reaching ambitious targets for renewable energy and transforming the energy supply to one based on renewables. However, as more wind is being deployed the available sites onshore become less attractive in terms of wind conditions and capacity factor and more resistance from population groups affected in the deployment areas results in a reduction of areas that can be developed. We consider three different methods for estimating acceptance costs, one based on compensation and property purchase costs, one based on property value loss near wind turbines, and one based on willingness to pay calculated from a stated preference study. Utilising these methods, we provide an estimation of Levelised Cost of Energy (LCOE) for an expansion in Denmark of onshore and offshore wind capacity of $12 \mathrm{GW}$. We find that the three methods provide similar estimates for local acceptance, but that a high range of uncertainty exists in the upper bound of acceptance costs. Onshore does not have a clear-cut cost advantage over offshore when considering substantial amounts of wind capacity expansion and using high estimates for nation-wide acceptance costs. Moderate onshore wind expansion considering only local acceptance has a cost advantage.
\end{abstract}

Keywords: wind energy; cost curve; preferences; public acceptance; offshore; LCOE

\section{Introduction}

Cost efficient deployment of wind energy is in focus for reaching ambitious targets for renewable energy and transforming the energy supply system to one based on renewables. Wind energy is one of the most cost-efficient renewable technologies and increasing amounts of wind energy is being installed in Europe and worldwide. In many countries, the cheapest wind resources on-shore are now competitive with conventional generation. However, as more wind is being deployed the available sites onshore become less attractive in terms of wind conditions and capacity factor and more resistance from population groups affected in the deployment areas results in a reduction of areas that can be developed. That means further onshore potentials become scarce and development has been moving off-shore.

Even though recent years have shown a significant decrease in costs for offshore wind, and as a consequence a narrower differential between onshore and offshore wind costs, offshore wind remains more expensive than onshore wind. As a consequence of the shift from onshore to higher cost offshore projects, the expansion of wind generation has become more expensive resulting in slower growth.

One fundamental question is whether the onshore potentials could be made available with compensation to the population groups affected by the deployment onshore, or if the willingness-to-pay for moving wind offshore is more considerable than the additional costs of developing offshore. This question is relevant to address if a cost-efficient deployment and a higher share of renewables are to be achieved. Here, the focus is on trying to determine the acceptance costs for Danish onshore development of wind, to add these costs to the primary development costs, and finally to compare this entire cost curve to the offshore wind costs.

When comparing costs of energy, the levelised cost of energy (LCOE) is a commonly used measure, which focuses on the cost of supplying energy (electricity) and do not include properties as the varying quality of supply and the fluctuating value of supply at different hours of the day and year. We are focusing on

* The authors are both with Systems Analysis Division, DTU Management Engineering, Technical University of Denmark 
comparing similar onshore and offshore wind development including different sites and conditions, but not fundamentally different technologies, generation profiles, lifetime etc. that would imply serious issues with LCOE comparability.

The LCOE expresses the cost over the lifetime of an asset related to the expected energy production, which is usually based on average annual production, and it furthermore accounts for the time value of money by discounting the cost and energy over the lifetime. There may be minor differences in the lifetime of turbines and the variability of the generation, but they are generally small within the wind technology, and therefore the LCOE is a reasonable measure for the comparison here.

A Danish partnership of different commercial and state entities has tried to propagate a standard approach to calculate the LCOE specifically for offshore wind energy (Forcherio, 2014) in order to facilitate a cost comparison of electricity production in a growing joined European energy system, but national practises involve various methods for the LCOE assessment.

\section{Onshore wind background, potentials and costs in Denmark}

The wind capacity onshore in DK is 3954 MW at the end of 2016 (Danish Energy Agency, 2017). The additional potential estimated by (Naturstyrelsen, 2014) based on reporting from Danish municipalities are $2860 \mathrm{MW}$ of which 1870 are in already designated planned areas. This adds up to approximately 6600 MW of long-term potential existing today.

This is a relatively conservative estimate and similar to data used in modelling analysis of generation capacity with a potential of around $6000 \mathrm{MW}$ in 2012 rising to around $8000 \mathrm{MW}$ for 2030, due to marginal expected additional planning and larger turbines (Balyk et al., n.d.). This is only a fraction of the possible technical potential of around $350 \mathrm{GW}$ if all areas are used regardless of land use constraints and impacts on dwellings (Danish Ministry of Taxation, 2016).

In (Energinet.dk, 2015b) an alternative method reach a total economically attractive onshore potential in DK of $12 \mathrm{GW}$ for the year 2030. This is a long-term potential (and uncertain) since it requires that all the relevant buildings in the immediate vicinity of future development can actually be purchased. We base our analysis of the onshore cost curve on this potential.

\subsection{Investment cost for onshore DK development}

Onshore investment costs have been declining globally and are now in the region $1000 \mathrm{EUR} / \mathrm{kW}$ to 1950 EUR/kW. For Denmark, it is assumed that investment costs will decline to around $1000 \mathrm{EUR} / \mathrm{kW}$ between 2020 and 2025. In comparison, the Technology Catalogue (Energinet.dk \& Danish Energy Agency, 2017) assumes a reduction from $1070 \mathrm{EUR} / \mathrm{kW}$ to $910 \mathrm{EUR} / \mathrm{kW}$ for the period 2015 to 2030 . Recent indication from manufacturers suggests that turbine prices have already dropped to just above $800 \mathrm{EUR} / \mathrm{kW}$.

For the construction of Danish cost curves, a value of $1000 \mathrm{EUR} / \mathrm{kW}$ is used independently of the amount of wind installation. It may be argued that larger volume of installation may increase the restriction on the technology used, including size (hub height), and noise-reducing designs resulting in rising investment cost for larger volumes. We do not include this possible effect and also do not consider further benefits from increased turbine size from the present size of 3-4 MW.

\subsection{Operation and maintenance costs}

The operation and maintenance costs are assumed to be proportional to generation at around 8-10 EUR/MWh annually. In comparison (The Danish Wind Turbine Owners' Association, 2014) reports an estimate around 11 EUR/MWh for lifetime O\&M cost for Danish onshore turbines. Costs may be reduced by longer lifetime for turbines in the future, due to slower technical progress (replacement with similar turbine) and a more substantial part of the remuneration from market income. Higher earnings from generation in later part of the lifetime may induce more maintenance effort than if support is earned only in the first 8-10 years. Due to this and a relatively stable turbine size, only minor reduction in maintenance cost must be expected. (Energinet.dk, 2016) estimates that present land wind requires a

* The authors are both with Systems Analysis Division, DTU Management Engineering, Technical University of Denmark 
market price of around 13-16 EUR/MWh to maintain profitability after the subsidy is expired, which is consistent with the slightly higher 0\&M costs (more than 10-11 EUR/MWh) at the end of turbine lifetime.

\subsection{Wind sites and the onshore Danish LCOE cost curve}

LCOE curves combine resource potentials with associated costs. The potentials can be represented as the annual generation or as capacity (MW) as will be done here. For a comparison of wind options with similar generation value (controllability), but different capacity factor (full load hours), and under similar economic constraints, the LCOE comparison is suitable and used here.

In Denmark, the lifetime assumptions were earlier for 20-22 years(Energinet.dk \& Danish Energy Agency, 2017), but this is expected to increase to now around 25 years for presently installed turbines. Naturally, the technical lifetime is longer than the economic lifetime and as maintenance costs decrease this also prolongs economic lifetime of turbines. Finally, the interest rate (discounting) used influences the LCOE with higher discounting of future electricity generation increasing the LCOE (see Figure 3). The low value of $4 \%$ used here (corresponding to social discount rate) reduce the LCOE relative to other studies using higher rates for example based on private financing cost calculations for business investing in wind development using WACC.

Apart from the cost side of the LCOE, the annual energy production (AEP) is the most critical parameter for the level of LCOE. Wind conditions and the power curve for individual turbines used will determine this. If we assume similar turbine designs (identical size, rotor diameter), the difference will be caused by the specific wind conditions (and topography) at the individual sites. In reality, there may also be variations in specific turbine designs for different wind conditions, but this is assumed to affect costs relatively little. The following data for Denmark include AEP variations, but not at the full microscale level. Figure 2 illustrates the realised capacity factor for recent onshore turbines in Denmark and Figure 1 the calculated capacity factor for the wind potential in (Energinet.dk, 2015b). Capacity factor is lowest for the turbines already in operation since 2010 (blue) compared to the larger and newer turbines in operation only from 2015 (red).

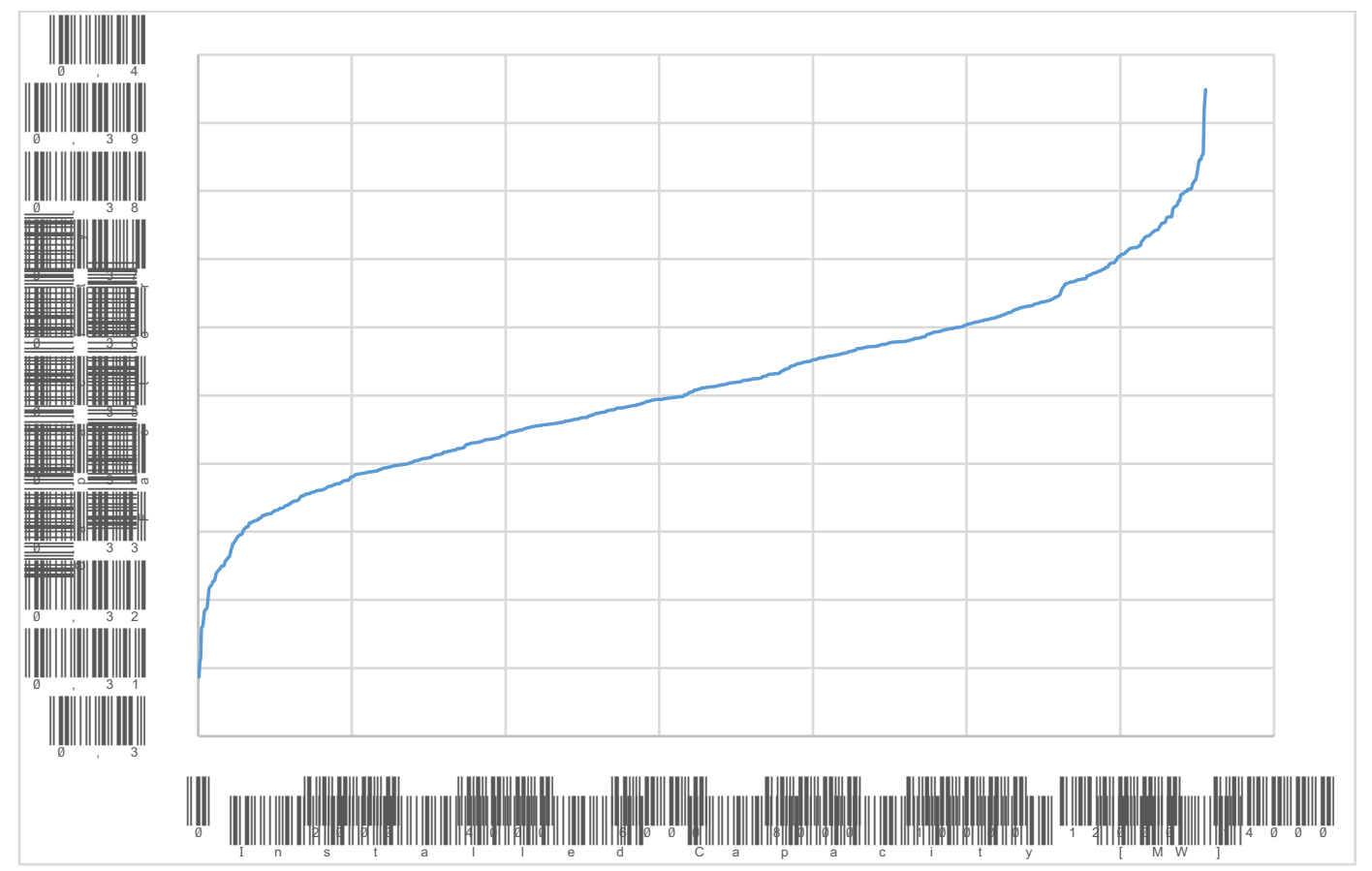

Figure 1: Capacity factor variation for future DK sites for onshore wind development with 3.5 MW (source:(Energinet.dk, 2015b))

* The authors are both with Systems Analysis Division, DTU Management Engineering, Technical University of Denmark 


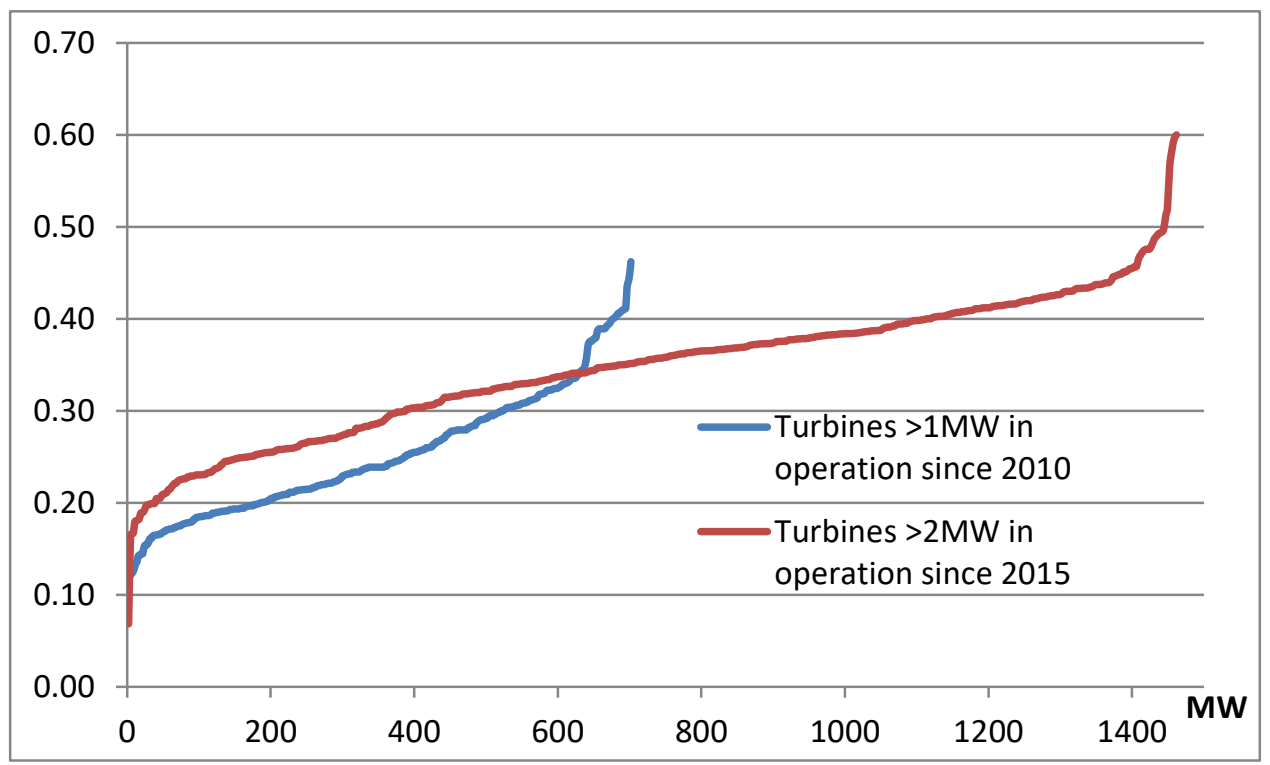

Figure 2: Realised capacity factor variation for larger DK onshore turbines in operation 2010-2016 (own calculation based on (Danish Energy Agency, n.d.))

Based on the realised capacity factor for newer larger turbines in Denmark it is reasonable to assume that future large turbines (3.5 MW) will achieve approximately the same average capacity factor of around $35 \%$.

In (Energinet.dk, 2015a) the attractive onshore potential in DK is around $12 \mathrm{GW}$ for the year 2030. This analysis is based on assessing the gross potential in areas where only a few dwellings will be affected and excluding areas with nature conservation constraints etc. The variation of capacity factor in Figure 1 is based on the (Energinet.dk, 2015a) identified 1000 sites and the 2008 wind profiles at these sites. The annual production for the turbines at the 1000 sites has been calibrated such that the average turbine has 3075 full load hours.

The analysis assumes turbines of size $3.5 \mathrm{MW}$ and only single $2600 \mathrm{~m}$ by $1200 \mathrm{~m}$ areas where either 3 or 5 turbines can be installed in a north-south direction requiring a maximum of 3 dwelling purchases. These are dwellings in the near vicinity of the turbines (less than $600 \mathrm{~m}$ corresponding to 4 wind turbine heights). The method is restrictive by not assessing options with less than three turbines or possible overlapping areas. However, the assumption on when it will actually be possible to purchase all the properties required is uncertain limiting the available short-term potential.

Comparing to international studies (Morthorst \& Kitzing, 2016; Wiser et al., 2011, 2016) our assumptions for investment cost, 0\&M cost, lifetime and wind conditions (capacity factor) are in similar ranges, and therefore the resulting LCOE is at the low end of the range seen in (Millborrow, 2016) and Figure 4. In (Millborrow, 2016) the sensitivity of LCOE to investment cost and wind speed is given for both onshore and offshore wind. Only the lower cost level $(1200 \mathrm{USD} / \mathrm{kW})$ is similar to our assumption of 1000 $\mathrm{EUR} / \mathrm{kW}$.

* The authors are both with Systems Analysis Division, DTU Management Engineering, Technical University of Denmark 

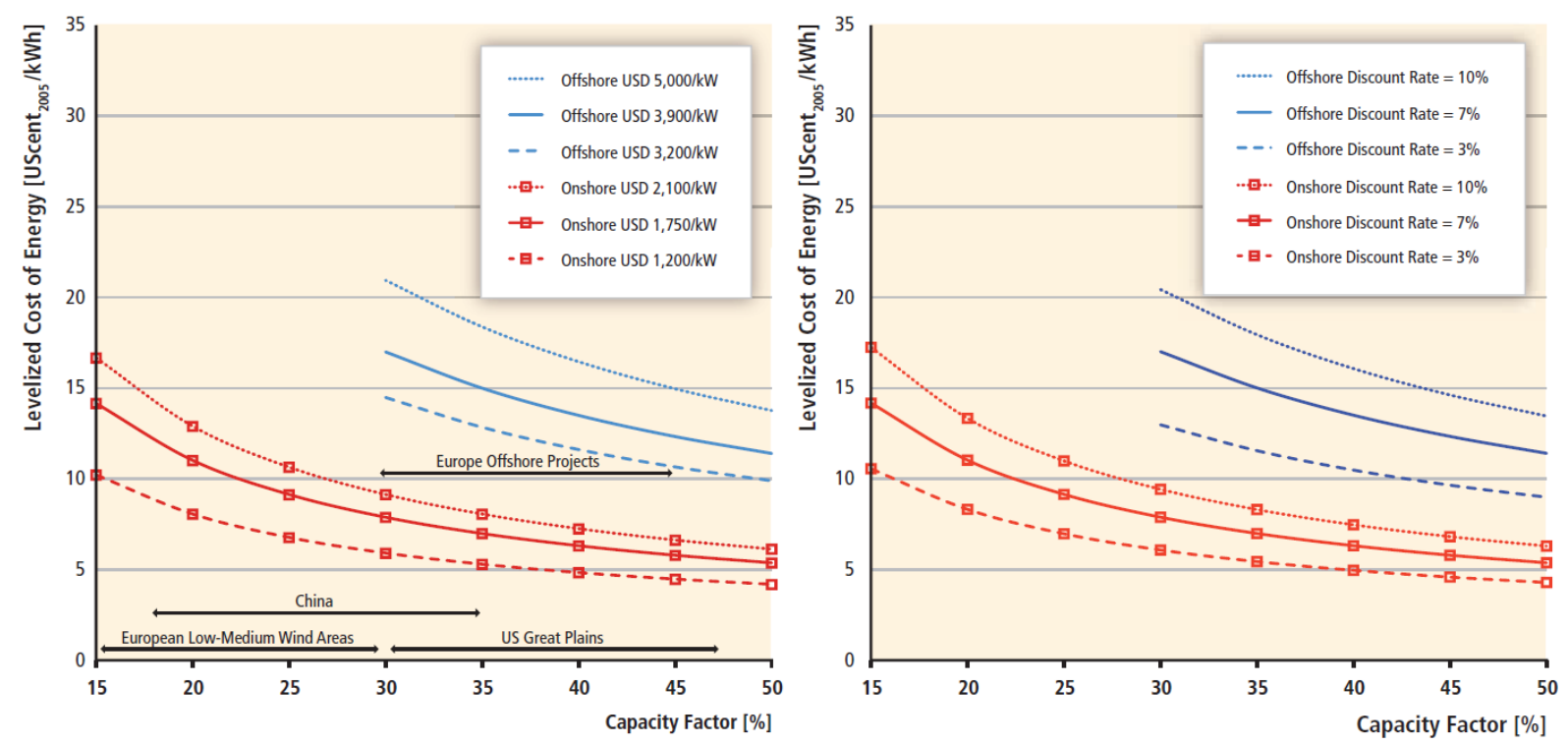

Figure 3: Estimated levelised cost of on- and offshore wind energy, 2009: as a function of capacity factor and investment cost* (left) and as a function of capacity factor and discount rate (right) (reproduced from ((Wiser et al., 2011))

Looking at estimates provided by (Wiser et al., 2011) shown in Figure 3, the left panel indicates an LCOE of 5 USD cents/kWh with low investment cost at a 35\% capacity factor. The right panel indicates a reduction of LCOE by 1.5-2 USD cents/kWh by reducing the discount rate from $7 \%$ to $3 \%$. Furthermore, (Wiser et al., 2011) illustrate the 2009 cost conditions and therefore the low-cost estimates may correspond with 2020-25 expectations for onshore. For offshore the general expectations for costs have been reduced following the recent price drops in auctions.

Thus for the low investment cost curve (1200 USD/kW) and a capacity factor around 35\%, the LCOE lies around 5-6 USD cents/kWh in the two studies, which has to be reduced slightly due to our use of a discount rate of $4 \%$ compared to the $7 \%$ used in the curves shown in Figure 3, left panel. The comparable Danish LCOE based on these studies should thus be in the range 3.5-4.5 USD cents/kWh corresponding to 3-4 c€/kWh.

(Morthorst \& Kitzing, 2016) state for offshore comparison that average onshore LCOE is around 5 USD cents/kWh for the low investment cost option (the same $1200 \mathrm{USD} / \mathrm{kW}$ ) considering a capacity factor between $30 \%$ and $40 \%$.

\section{Offshore wind background in Denmark, cost drivers and international comparison}

\subsection{Current status of offshore wind energy in Denmark.}

Offshore wind energy has been growing in Denmark in a sustained manner, since the first offshore wind turbine park, Vindeby, was erected in 1991. As of 2017, there are 12 offshore wind turbine farms in Denmark, since the decommissioning of the Vindeby park, with a total installed capacity of $1271 \mathrm{MW}$ (Danish Energy Agency, 2015). A list of existing offshore wind energy farms and some necessary information is found in Table 1.

* The authors are both with Systems Analysis Division, DTU Management Engineering, Technical University of Denmark 


\begin{tabular}{|c|c|c|c|c|c|}
\hline Wind Farm & $\begin{array}{c}\text { Lifetime } \\
\text { Capacity } \\
\text { Factor }\end{array}$ & $\begin{array}{c}\text { Age } \\
\text { [Years] }\end{array}$ & $\begin{array}{c}\text { Installed } \\
\text { Capacity } \\
\text { [MW] }\end{array}$ & $\begin{array}{c}\text { Depth } \\
\text { [m] }\end{array}$ & $\begin{array}{c}\text { Distanc } \\
\text { e to } \\
\text { shore } \\
{[\mathrm{km}]} \\
\end{array}$ \\
\hline Anholt 1 & $48.6 \%$ & 4 & 399.6 & 17 & 18 \\
\hline Avedøre Holme & $38.0 \%$ & 7 & 10.8 & 1 & 0 \\
\hline Frederikshavn & $30.5 \%$ & 14 & 7.6 & 4 & 3 \\
\hline Horns Rev I & $41.8 \%$ & 15 & 160 & 10 & 17 \\
\hline Horns Rev II & $47.7 \%$ & 8 & 209.3 & 13 & 30 \\
\hline Middelgrunden & $25.4 \%$ & 17 & 40 & 4 & 5 \\
\hline Nysted (Rødsand) I & $37.0 \%$ & 14 & 165.6 & 8 & 11 \\
\hline Nysted (Rødsand) II & $43.4 \%$ & 7 & 207 & 9 & 9 \\
\hline Rønland I & $44.5 \%$ & 15 & 17.2 & 1 & 0 \\
\hline Samsø & $39.1 \%$ & 15 & 23 & 12 & 4 \\
\hline Sprogø & $34.2 \%$ & 8 & 21 & 11 & 11 \\
\hline Tunø Knob & $30.2 \%$ & 22 & 5 & 5 & 6 \\
\hline Vindeby (closed) & $21.6 \%$ & 26 & 5.0 & 3 & 2 \\
\hline Total & $41.4 \%$ (avg.) & 13.2 (avg.) & 1271 & $\begin{array}{c}7.5 \\
\text { (avg.) }\end{array}$ & $\begin{array}{c}8.9 \\
\text { (avg.) }\end{array}$ \\
\hline
\end{tabular}

It is expected for offshore wind to keep expanding in future years, as part of the strategy regarding renewable energy goals. Currently, there are eight projects assigned for environmental impact assessment or development with a total nameplate capacity of up to $2.2 \mathrm{GW}$ : Horns Rev 3, Kriegers Flak, Vesterhav Nord og Syd, Nissum Bredning, Omø Syd, Jammerland Bugt, Mejl Flak, and Lillebælt Syd. Furthermore, a number of tenders have been carried out for the development of new offshore wind energy farms. Some of the tender areas are offshore locations close to the shore, which aim to lower the costs for installing and operating the wind turbines, as for example Sejerøbugten, Smålandsfarvandet and Sæby (Danish Energy Agency \& Energinet.dk, 2013).

\subsection{Costs for Offshore wind}

In comparison with onshore wind farms, constructing offshore wind turbines is a more expensive undertaking, and significantly capital-intensive. Furthermore, costs will vary greatly depending on the location, due to water depth, distance to coast, sea conditions, and more (Kitzing \& Morthorst, 2015).

\section{Investment costs}

Commonly the total investment costs are broken down into various cost components. By presenting different shares for the cost components, different projects can be compared with each other in more detail, since for instance the effects of the geographical characteristics of the offshore wind farms on the investment can be revealed. The comparison of different wind farms, however, in general, is more accurate for projects with similar commissioning time, similar geographical characteristics or comparable technical characteristics as for instance the type of turbines or the installed capacity.

Table 2 presents different cost breakdowns of offshore wind farms found in the literature for different publication years. The inclusion of components differs when looking at the different cost breakdowns, making it challenging to allocate different costs where they actually arise. Mainly, the installation cost is sometimes not reflected independently in presented cost breakdowns, leading to a distortion of the remaining cost component shares. Also, the cost for electrical components is sometimes not addressed in cost breakdowns, due to the fact that these components are not always included in the project scope of the wind farm investor, but are constructed and invested by other entities. The problem of different investment cost splits throughout the literature has been mentioned by (Voormolen et al., 2015).

* The authors are both with Systems Analysis Division, DTU Management Engineering, Technical University of Denmark 


\begin{tabular}{lccc}
\hline & EWEA (2009) & IRENA (2012) & Kitzing \& Morthorst (2015) \\
\hline Turbine & $49 \%$ & $44 \%$ & $40 \%-60 \%$ \\
Foundation & $21 \%$ & $16 \%$ & $20 \%$ \\
Electrical & $21 \%$ & $17 \%$ & \\
Installation & & $13 \%$ & $25 \%$ \\
Other & $9 \%$ & $10 \%$ & \\
\hline
\end{tabular}

Table 2: Indicative cost breakdowns of offshore wind farms in the literature

\section{Operation and maintenance costs}

Operation and Maintenance costs (O\&M) or OPEX are expressed within the annual costs after commissioning of the farm and tend to increase over the farm's lifetime. The 0\&M costs are either expressed as variable cost per MWh generated or as a fixed cost per MW installed capacity. This is due to the fact that different parts of OPEX are variable cost, such as repair costs and to a certain extent spare parts and maintenance (which are likely to be related to the production level) and other parts are fixed costs, such as insurance costs, administration and regular maintenance (which are likely to be related to the fixed installed capacity. According to (Energinet.dk \& Danish Energy Agency, 2017), for 2015 fixed O\&M costs are 57,300 EUR/MW/year, while the variable costs are $4.3 \mathrm{EUR} / \mathrm{MWh}$.

One can combine the variable cost depending on the energy produced and the residual fixed cost to obtain the total OPEX cost. For offshore wind, the variable part of the OPEX is estimated to be half of the total OPEX (Voormolen et al., 2015). In the literature it is estimated to be in a range of 15-49 EUR/MWh (Kitzing \& Morthorst, 2015) in variable terms and 2.2\%-4\% in fixed terms as share of CAPEX (DECC (Department of Energy \& Climate Change), 2013; Heptonstall et al., 2012; Prässler \& Schaechtele, 2012). Over the total lifetime of the farm, the OPEX can encompass $25-30 \%$ of the total project cost (Kitzing \& Morthorst, 2015).

Considering the aforementioned geographical cost drivers, mostly the distance to the nearest maintenance port directly affects the OPEX, due to the cost connected to the travel time of the maintenance vessel and potentially rougher weather conditions at sites further offshore, which constrain the operation time on site. After assessing the total cost of a wind farm project, the LCOE can be estimated when predicting the energy generation of the farm over the total lifetime.

\subsection{The Danish offshore LCOE cost curve}

As with the Danish onshore cost curve, we are interested in creating a cost curve that combines the potential exploited with the associated cost of doing so, for offshore wind energy. Factors that affect the costs for different potentials include three general categories: technical costs that will vary with water depth and distance to shore, costs associated to availability and profiles of wind in the area, and costs associated with the social impact produced by the wind farm.

From a technical perspective, as different wind sites are exploited, two main variables will affect these previous costs: distance to shore, and water depth. Technical costs will be affected by both variables: as water depth increases it becomes more expensive to install the wind turbines, and at specific water depths, more expensive foundation technologies have to be used. Similarly, as the distance to shore increases, $0 \& \mathrm{M}$ becomes more expensive and the costs for cabling during installation, as well as the costs related to port availability and installation time increase as well. Offshore wind energy cost curves will be increasing due to developing sites first that present lower cost, either due to being sites with better wind potential conditions, or with conditions that make investment costs lower (water depth).

Based on data obtained by the RESOLVE model, and presented in (Beurskens \& Hekkenberg, 2011), we construct a cost curve for offshore wind potential in Denmark that considers a total offshore wind expansion potential of $10.7 \mathrm{GW}$. Based on the data and cost levels available at the time the LCOE levels range between $9 \mathrm{c} € / \mathrm{kWh}$ for small amounts of exploited potential, climbing steadily up to approximately $17 \mathrm{c} € / \mathrm{kWh}$ before spiking up to a final level of $19.9 \mathrm{c} € / \mathrm{kWh}$ for the full potential. These estimates are consistent with several other studies finding prognosis of offshore wind LCOE (Fichtner/prognos, 2013;

* The authors are both with Systems Analysis Division, DTU Management Engineering, Technical University of Denmark 
Fraunhofer ISE, 2013; IRENA, 2012; Mone et al., 2015; The Crown Estate, 2012; TKI Wind op Zee, 2015), a selection of which is shown in Figure 4. It is interesting to note the extensive range of uncertainty regarding the levels of LCOE prognosticated.

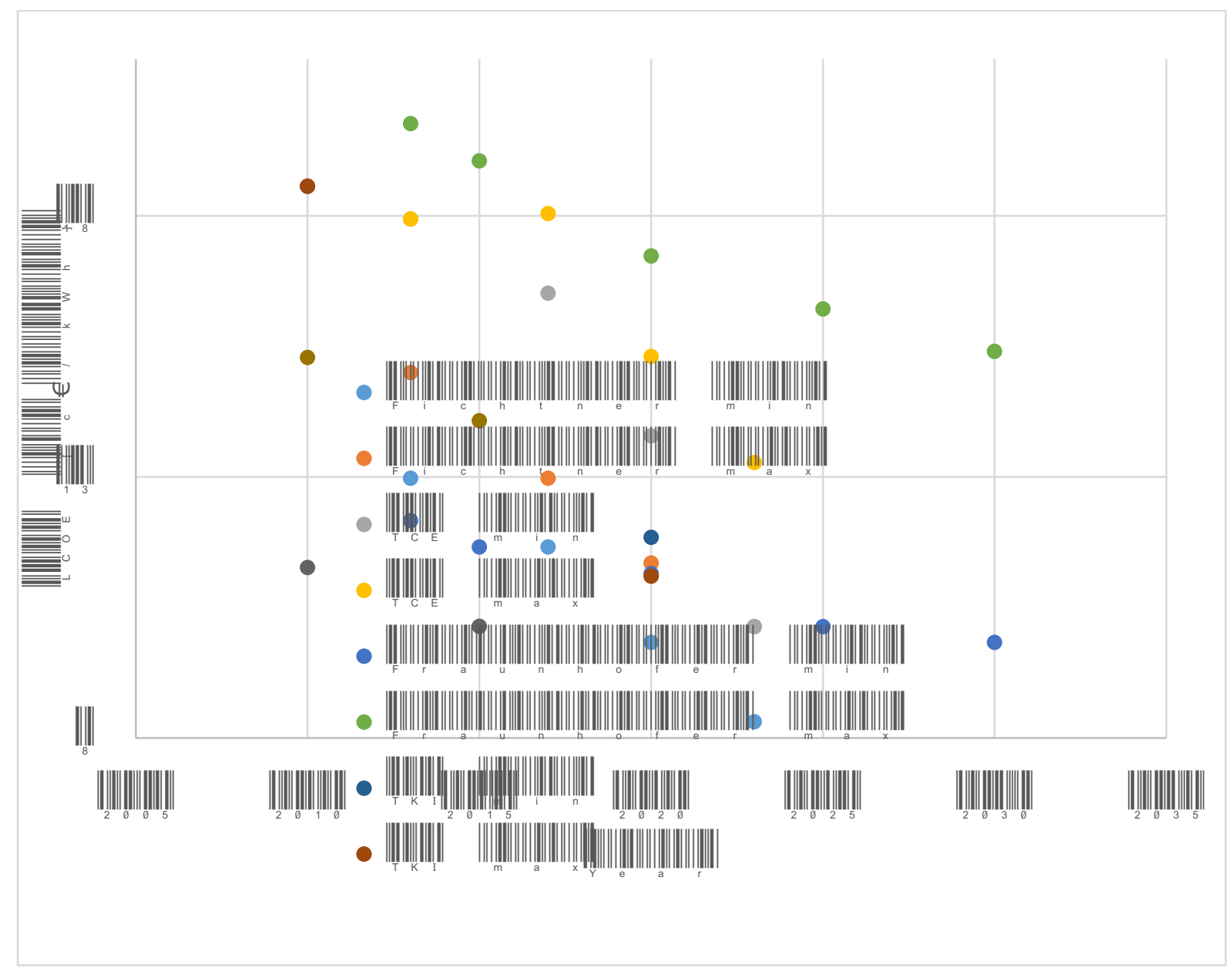

Figure 4: LCOE prognosis for offshore wind, own work based on (Fichtner/prognos, 2013; Fraunhofer ISE, 2013; International Renewable Energy Agency, 2012; The Crown Estate, 2012; TKI Wind op Zee, 2015).

Recently, offshore cost estimates have dropped significantly for Denmark and elsewhere, as evidenced by the Kriegers Flak project with a winning bid of $4.9 \mathrm{c} € / \mathrm{kWh}$. Interestingly, this development presents a level below any of the existing LCOE estimates. For this reason, we adjust the cost curve under the assumption that while the initial level of the costs has changed significantly faster than expected, the drivers for the cost increase of exploiting larger amounts of potential have not. Both curves, the original levels given by (Beurskens \& Hekkenberg, 2011) and the adjusted ones, are presented in Figure 5.

* The authors are both with Systems Analysis Division, DTU Management Engineering, Technical University of Denmark 


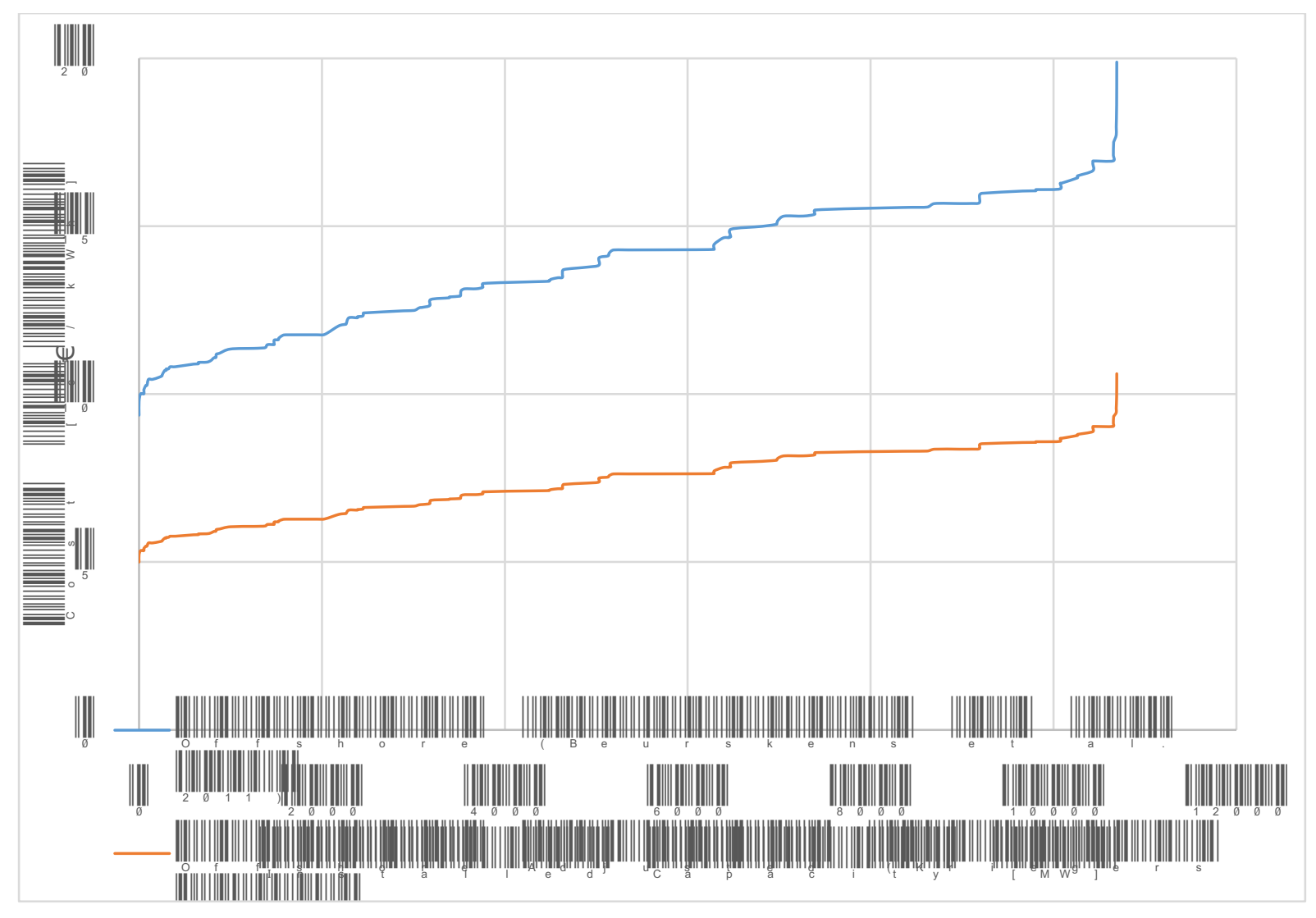

Figure 5: Original and scaled offshore LCOE curve

Great care has to be taken when utilising LCOE measures for comparing projects sited in different countries. For the present study, all projects considered have been analysed under a similar regulatory framework, which makes comparison among them possible.

\section{Methods for calculation of acceptance costs}

Theoretically, acceptance costs for wind turbines should contain all externalities associated to the project being studied including use and non-use values. From a practical perspective, though, acceptance costs will be expressed via compensation payments, project development costs associated to local resistance, and similar additional costs. Evidently, these costs may be different for every person, and as such, the total acceptance costs should be aggregated based on these differences. Due to their extensive definition, the total acceptance costs are not directly measurable; nonetheless, in many cases, these costs can be approximated by looking either at legislation, standard practices, or various preference studies, either revealed or stated.

There are different extensions over which acceptance costs can be considered. In the present study, we consider two scopes: the localised acceptance costs, that encompass only the costs borne by the people living in the area directly affected by the proposed projects; and the nationally aggregated acceptance costs, that encompass the whole population of Denmark. While both scopes present generalisations, and therefore numerous sources of error, they provide us with a range of levels that will help define bounds.

We will utilise three different approaches for estimating acceptance costs of the expansion of onshore wind energy in Denmark:

A. Acceptance costs calculated using actual potential wind sites in Denmark, with compensation payments derived from the actually paid compensations, calculated payments to green funds, and calculated costs of offering shares to local residents

* The authors are both with Systems Analysis Division, DTU Management Engineering, Technical University of Denmark 
B. Acceptance costs based on other researchers' revealed preference studies of average property value loss and the number of properties affected by the potential development at the same actual sites as in A.

C. Acceptance costs estimated based on a stated preference study, which considers different onshore and offshore scenarios, with varying, technologies, sites, and costs in Denmark. These values can then be aggregated to either a local acceptance scope, considering only the households defined in A, or to a national population level.

These acceptance costs are assigned to individual potential sites and can thereby later be added to the basic wind turbine development cost at these specific sites, with which we can estimate a total LCOE cost curve for the expansion of wind energy in Denmark that accounts for acceptance costs.

\subsection{Acceptance cost based on compensation schemes and property purchase} (A)

The first method is using the data developed by (Energinet.dk, 2015b) and made available for this analysis. The estimated compensation payments can be used as an approximation for the local acceptance costs interpreted as the minimum additional costs that are required to realise these projects.

The Energinet.dk analysis provides an onshore potential with the associated cost of adding sites including the marginal cost of purchasing specific dwellings around each site at $150 \%$ of the property tax value base and adding other compensating costs.

The marginal costs included in the assessment are:

1. Purchase of buildings within $600 \mathrm{~m}$

2. Compensation for impacts on buildings within the designated area but further away than $600 \mathrm{~m}$. $(600 \mathrm{~m}-1500 \mathrm{~m})$

3. Cost of providing $20 \%$ asset share for locals

4. Green Fund contribution to municipality

The most substantial impacts are seen from the purchase of buildings $(150 \%$ of property value reduced by land value), and it is this cost element that contributes to the increase at the end of the total cost curve seen in Figure 6. The cost includes EUR 13,400 (100000 DKK) per property for demolition cost.

Compensation calculation is based purely on the distance from the turbine to the house, the value of the house, and an estimated relationship between compensation approved and this distance. It builds on data for around 310 cases that have received compensation payment under this DK scheme (up to 2014). The total compensation approved has been 4.4 MEUR (33 MDKK), with a considerable variation in compensation ratio (ranging from $5 \%$ to $75 \%$ of the property value).

The last cost components correspond to the mandated offering of $20 \%$ of the ownership share of the project to locals at a direct cost price, and to the green fund contribution. This amounts to a rough estimate for each turbine of 0.3 MEUR (2.23 MDKK) for the ownership share and 0.05 MEUR (0.3 MDKK) per turbine for the green fund contribution.

\subsection{Acceptance cost based on property value loss data (B)}

This approach compares the acceptance cost from the same potential sites as in A, but then the properties in the vicinity are assigned a property value loss based on an assumption using results from (Jensen et al., 2014). The number of properties affected is based on detailed information provided by Energinet.dk combined with an average property value for each site. This approach does not include the purchasing of any buildings, but the 4700 properties purchased in method (A) are added to the 129,000 properties receiving compensation in (A). All the properties within $1,500 \mathrm{~m}$ from a turbine are thus treated identically. No additional cost of compensation, green fund etc. are added in this case since the full property value loss is interpreted as an alternative or just as the externality that the compensation payments etc. are intended to cover.

* The authors are both with Systems Analysis Division, DTU Management Engineering, Technical University of Denmark 
The central assumption for the calculation is an average value loss of $10 \%$ for all dwellings within 1,500 $\mathrm{m}$ of a turbine. This is within the hedonic price estimates (Jensen et al., 2014), for the dwellings where the turbines are visible within a distance of up to $1.6 \mathrm{~km}$. They isolate visual and noise effects on the house prices and for the purpose here we treat their Table 5, "Distance as proxy" combined effect as the average effect for dwellings in the 1,082 potential wind development areas, further assuming that the average dwelling will be around $800 \mathrm{~m}$ from the turbines corresponding to a $10.1 \%$ value loss. We thus use an assumption of a $10 \%$ value loss for all the dwellings within $1,500 \mathrm{~m}$ of a turbine. This approach will overestimate the number of houses with the visual effect as the (Jensen et al., 2014) study notes that only around $33 \%$ of houses within the $1,600 \mathrm{~m}$ distance had a visual impact from the house. The average number of dwellings affected for the 1,082 sites is thus 123 .

Using these assumptions we get a substantial variation in the calculated property value losses that are primarily a result of varying number of dwellings in the areas, and secondarily an effect of varying average value for the dwellings.

\subsection{Acceptance costs based on stated preference data (C)}

This third method is not based on data regarding existing economic transactions, like the two previously presented methods, but on responses to a survey detailing a hypothetical situation. While the previous two methods are able to give real measures of the actual costs experienced, they are not able to consider hypothetical future situations (and therefore possible scale effects) or to consider an extensive range of non-use values, such as those experienced by people living away from the local area affected by previous developments. For this reason, it is of interest to have a measure of acceptance costs that is able to account for these two elements.

In recent years, numerous studies have approached acceptance costs and environmental valuation of wind turbines by the utilisation of stated preference, and in particular choice experiments (Hevia-Koch \& Ladenburg, 2016). In these experiments, by presenting respondents with choice sets where they have to repeatedly choose one hypothetical scenario among a number of other scenarios with different attributes, such as cost, number of turbines, the location of the turbines, or size of the turbines. Based on the responses given by respondents, it is possible to estimate the influence of each attribute on the preferences of the respondents. Furthermore, by comparing the ratio of the influence of a specific attribute with the cost attribute, one can calculate the willingness-to-pay (WTP), a monetary measure of the value respondents place on a specific attribute. If one were to utilise this WTP as a measure of acceptance costs, it would be necessary to aggregate it in regards to the relevant population.

While there exist numerous studies calculating WTP for wind turbines, few studies attempt to find an aggregate measure of cost based on their estimated WTP regarding different siting or technology options for wind turbines. One such study is the study done by (Krueger et al., 2011), where they calculate the total annual willingness to pay for $450 \mathrm{MW}$ wind capacity shifted from $1.4 \mathrm{~km}$ to out of sight distance for the entire population (number of households) in the state of Delaware. The aggregated annual sum of 6.5 MEUR (7.6 MUSD) is then compared to US estimates of reducing costs by moving wind turbines closer to shore. These numbers are in the same range, 6.8-8.6 MEUR additional external costs per mile compared to 6-17 MEUR cost savings per mile. A very rough assumption would be that the annual acceptance costs of onshore wind turbines compared to far ashore turbines are 6.5 MEUR for the $450 \mathrm{MW}$ of capacity. This is around 0.4 EUR cents in additional acceptance cost for onshore wind expansion. Comparing to our results for Denmark, this corresponds to the acceptance cost level associated to an onshore wind development of between 3 to $6 \mathrm{GW}$, depending on if method (A) or (B) is used (see Figure 6, Figure 7). Therefore, the level estimates obtained by the comparable Delaware study are contained in our estimates of the acceptance cost range obtained with method (A) and (B).

The precision of these cost estimates is a subject under discussion since there is evidence of the existence of several biases that affect the responses given by respondents. In addition, it has been seen that the results obtained regarding respondents' preferences on a choice experiment are sensitive to the formulation of the experiment, its questions, and the information presented in it (both quantity and the media used to display it). Therefore, it is paramount to rigorous in both in the study design, as well as the

* The authors are both with Systems Analysis Division, DTU Management Engineering, Technical University of Denmark 
interpretation of the results obtained by it (Hanley et al., 1998; Hevia-Koch \& Ladenburg, 2016). Nonetheless, stated preferences studies, and particularly choice experiments provide valuable information and valid measures of the respondents' preferences, and therefore in this case on the acceptance costs for wind turbines.

For calculating the acceptance costs, we utilise data from (Hevia-Koch et al., 2018), an internet-based choice experiment conducted in 2012 that examines preferences of Danish respondents regarding offshore and onshore wind turbines. The sample consists of 1753 different respondents, randomly selected as representation of the Danish national population. In this experiment, respondents are presented with a hypothetical development of $450 \mathrm{MW}$ of wind energy in Denmark, distributed either as a single offshore wind turbine farm or as small onshore wind farms of 1 to 4 turbines, distributed amongst different areas of Denmark. Each respondent is presented with eight choice sets of two different alternatives, one offshore and one onshore, with varying attributes (therefore, there is a total of 14024 observations). Tables summarising the estimated WTP and the sample statistics can be found on the Appendix. For a thorough description of the model formulation and the estimation results, please refer to (Hevia-Koch et al., 2018).

While the study calculates several preferences and their associated WTP, we are interested in a measure of the acceptance costs associated to onshore wind turbines. Therefore, the value we are interested in is the WTP associated with putting wind turbines offshore instead of onshore (presented as the WTP associated to the offshore alternative specific constant in the choice experiment). In effect, the amount respondents are willing to pay to remove onshore wind turbines and site them offshore is a measure of the acceptance cost of having onshore wind turbines.

The calculated WTP for siting wind turbines offshore is 82.77 EUR (612.5 DKK) per household per year; nonetheless, this value is an average for the sample population of the study, which bears differences to the Danish national population, particularly in regards to age. For this reason, we re-estimate the WTP for siting wind turbines offshore as a function of age and create a weighted average that considers the age distribution of Denmark, resulting in a WTP of 73.10 EUR (541 DKK) per household per year. It is important to note that the design of the survey presents the respondents with a situation where the proposed onshore turbine is either in their own municipality or a neighbouring one, and therefore respondents answer based on the possibility of having the onshore turbines nearby their homes.

When deciding which population group to be considered when aggregating acceptance costs, there is no simple answer. The precise identification of which citizens are affected by the proposed wind turbines is an arduous task, which requires a level of precision in data beyond the scope of this study. As an alternative, we define two bounds: a higher and a lower acceptance cost. We define the higher acceptance cost as the cost that considers every household in Denmark. This measure is extensive in terms of the amount of population considered. It is relevant to note that due to the design of the survey, we consider as if all of the population of Denmark was exposed to the possibility of having an onshore wind turbine near their home, which provides a measure of WTP that is higher than one considering realistic measures of who would be affected. On the other hand, we define the lower acceptance cost as the cost considering only the households that are considered to be compensated or bought due to the expansion of onshore wind turbines, as presented by the Energinet.dk analysis. This measure is restrictive, in the sense that it excludes any person not living in the immediate area of the proposed wind turbines, and ignores any costs not associated to the local environment. These two measures, then, define the region over which the acceptance cost lays. The calculation of the two measures is presented in Table 3:

\begin{tabular}{ccc}
\hline & $\begin{array}{c}\text { Number of } \\
\text { households }\end{array}$ & $\begin{array}{c}\text { Aggregated Avg. } \\
\text { WTP/MW/year [EUR] }\end{array}$ \\
\hline $\begin{array}{c}\text { Lower acceptance } \\
\text { cost }\end{array}$ & 133.764 & 21.747 \\
$\begin{array}{c}\text { Higher acceptance } \\
\text { cost }\end{array}$ & 2.670 .059 & 434.095 \\
\hline \multicolumn{2}{c}{ Table 3: Lower and higher acceptance costs }
\end{tabular}

* The authors are both with Systems Analysis Division, DTU Management Engineering, Technical University of Denmark 


\section{Results for offshore and onshore wind costs including acceptance}

\subsection{Acceptance cost based on method A}

The three cost components follow an entirely different path with increasing onshore wind. Examining the total LCOE costs per MW capacity in Figure 6, the cost share of $20 \%$ asset ownership is a constant addition corresponding to $5-10 \%$ of costs and the green fund cost share is negligible. The compensation payments are small, rising with the developed amount and varying a lot near the $12 \mathrm{GW}$ of accumulated development, but with no significant accumulated cost contribution. The main contribution to the total cost is the purchase of property, which amounts to close to $30 \%$ of total cost for the last GW up to the economically attractive $12 \mathrm{GW}$.

The cost curve based on Energinet.dk data is the addition of basic technology cost and implementation cost (acceptance). Implementation costs are here interpreted as a proxy for externality costs and therefore similar to the costs derived from preference studies of attitudes (willingness to pay) towards moving turbines from onshore to offshore sites. The approach in (Energinet.dk, 2015b) and with data used here is giving emphasis to externalities of the few people with residence close to a wind turbine. The number of households affected for a $12 \mathrm{GW}$ expansion of wind corresponds to around 3400 dwellings. The average cost of purchasing these properties is around EUR 900,000. For the most expensive areas to reach $12 \mathrm{GW}$ the total cost of purchasing the properties in the area matches the investment cost of the turbines.

When comparing these results to the externalities derived from stated preference studies, we can see that stated preference studies emphasise the lesser effects from visual impacts on a larger number of people living in the larger vicinity of more than $1500 \mathrm{~m}$ from the wind turbines. On the other hand, the approach taken used in (Energinet.dk, 2015b) is not affected by these extended effects.

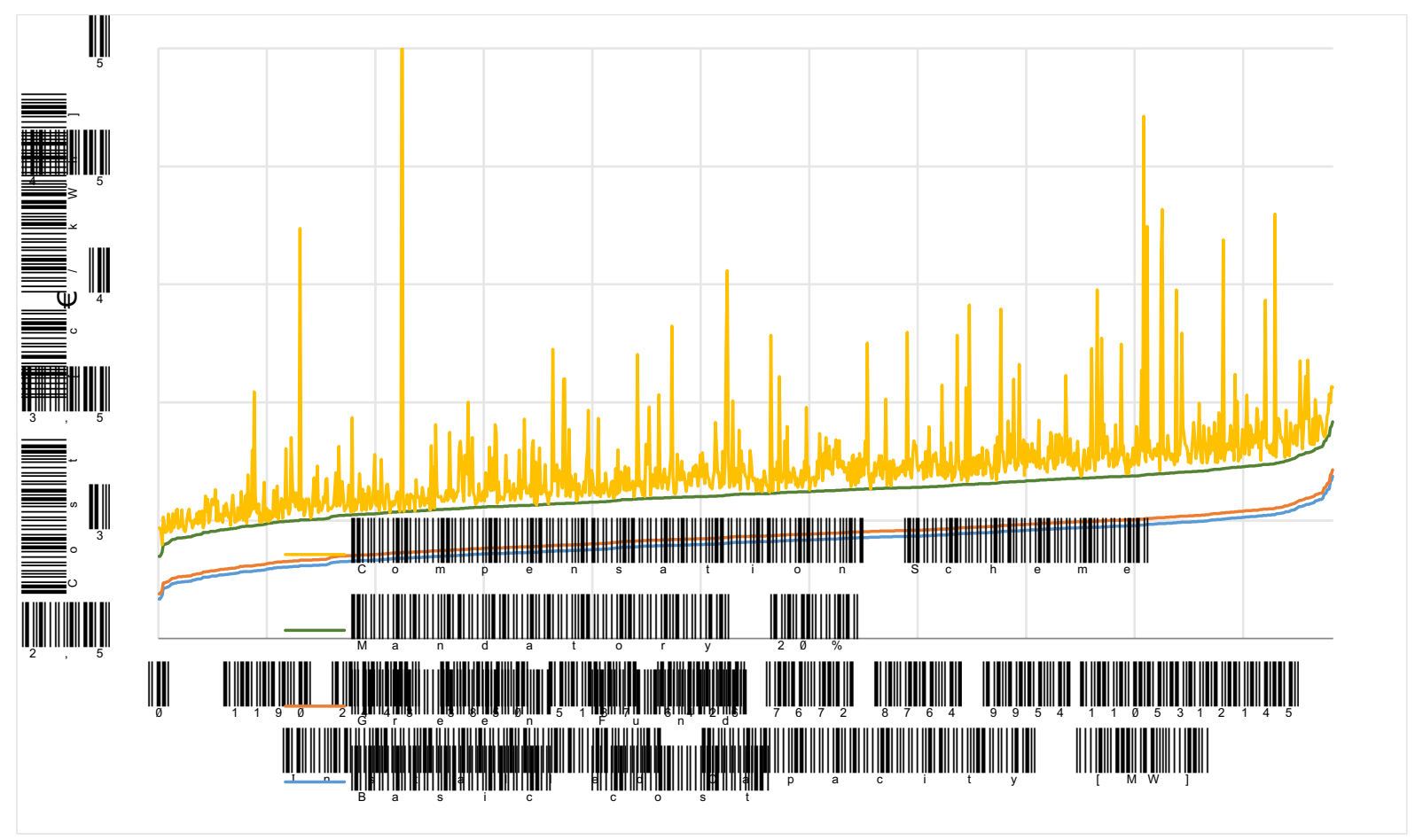

Figure 6: LCOE elements from the three compensation schemes in place in DK sorted by basic development cost

* The authors are both with Systems Analysis Division, DTU Management Engineering, Technical University of Denmark 
Comparing the LCOE from the Energinet.dk study with the global estimate of onshore wind LCOE provided by (Millborrow, 2016) for the low investment cost option (1200 USD $/ \mathrm{kW}$ - and 40\% capacity factor light blue in his graph) Energinet.dk is considerably lower for at least $6 \mathrm{GW}$ of onshore capacity in DK. It is assumed that this is caused by assumptions on operation and maintenance cost, lifetime and discount rates.

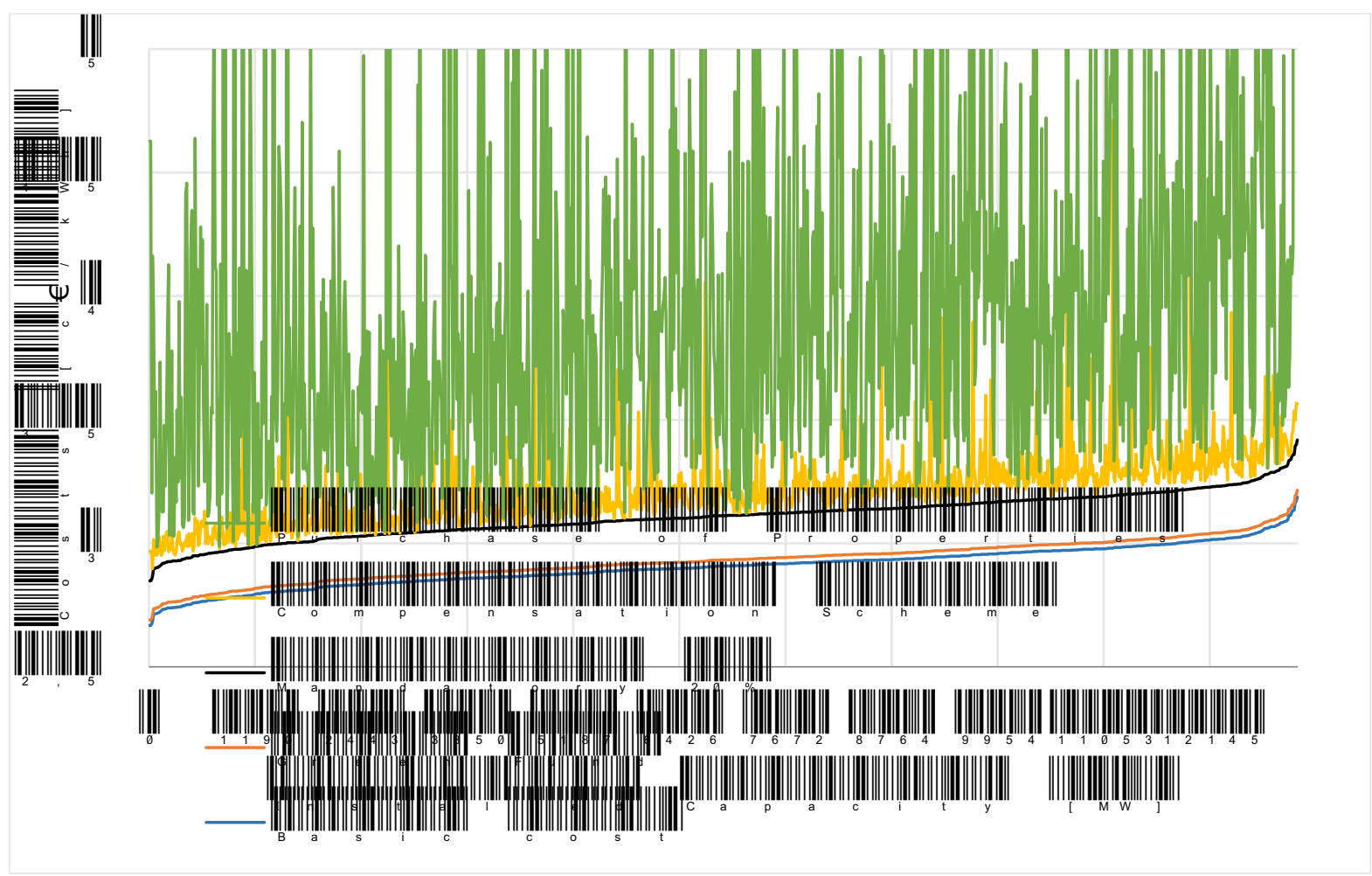

Figure 7: Components of cost in the total LCOE including property purchase sorted according to basic development cost

The general conclusion from Figure 7 is that the variation of property purchase costs dominates the variation in all other costs and determines the final ranking. If the most economical sites to reach a total $12 \mathrm{GW}$ were to be identified, all the sites in Figure 7 with costs above $5.05 \mathrm{c} € / \mathrm{kWh}$ should be excluded. The result of this ranking is illustrated in Figure 9 below.

\subsection{Acceptance costs based on method B}

The costs from value loss of houses located more than $600 \mathrm{~m}$ from turbines is increasing with the amount of capacity being installed. The curve in Figure 8 is increasing with some variation due to the sorting of the sites being based on the total cost for method B including basic wind turbine costs and wind conditions. The value loss for the houses within $600 \mathrm{~m}$ distance is following a similar trend but is at a much lower level than using method A since their individual value loss calculated in method B is much lower than using the purchase costs. Therefore the sorting according to method B will be less influenced by the variation in purchase costs among the different areas and to a larger extent just the number of houses affected in total.

* The authors are both with Systems Analysis Division, DTU Management Engineering, Technical University of Denmark 


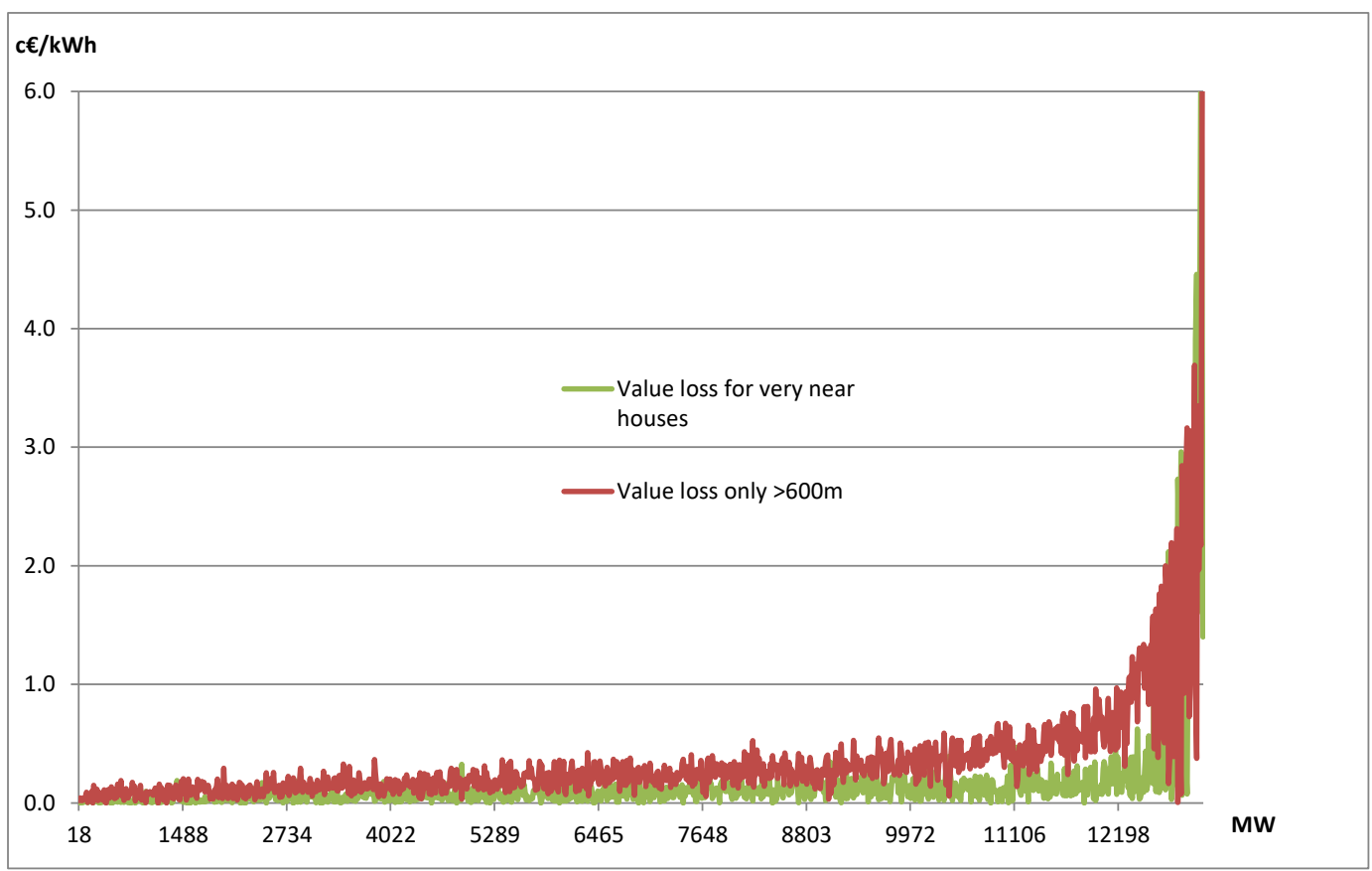

Figure 8: Value loss elements based on method B

For the total acceptance cost by method B the increase is gradual until a capacity level of around $10 \mathrm{GW}$, where it is less than $1 \mathrm{c} € / \mathrm{kWh}$. Method B provides lower acceptance cost results than method A.

\subsection{Acceptance costs based on method C}

The two measures from Table 3 are transformed to $€ € / \mathrm{kWh}$ by considering the relevant capacity factors for the possible onshore projects. Considering only the averages gives a flat cost curve, which is a reasonable measure when considering the High Acceptance Cost bound since it considers all of the Danish population at once. On the other hand when calculating the Lower Acceptance Cost, one should consider that future exploitation of the wind potential in Denmark will follow a similar pattern as the one assumed by Energinet.dk, where the cheapest sites are exploited first. Therefore, the lower acceptance cost curve is modified by creating a curve that maintains the total cost per kWh but follows the shape of the cost curve presented by (Energinet.dk, 2015b). Since the high acceptance cost already considers all of the population in Denmark, and is defined as a high bound, we do not modify the shape of that curve. Figure 8 presents both the resulting high and low acceptance cost curves, compared to the basic cost curve.

* The authors are both with Systems Analysis Division, DTU Management Engineering, Technical University of Denmark 


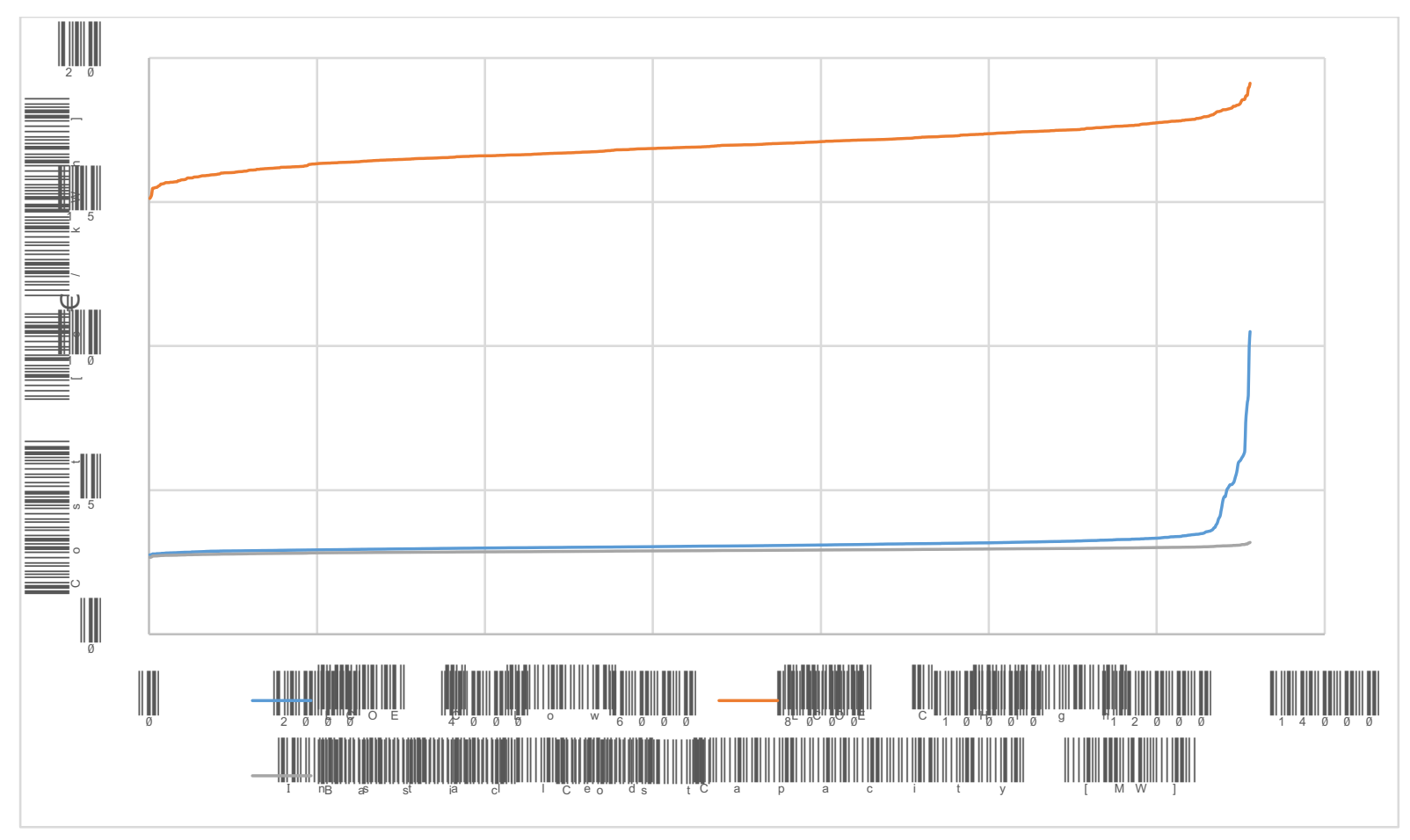

Figure 9: High and low acceptance cost curves

\subsection{Addition of acceptance cost and basic cost}

For the sum of basic onshore costs and acceptance costs, we use the primary cost curve for the $13 \mathrm{GW}$ onshore capacity in 2030 sited in 1082 areas with specific wind conditions given by (Energinet.dk, 2015b). We then independently add the acceptance costs obtained from method (A), (B) and (C). These methods illustrate a span of total onshore wind development cost to be compared with the offshore development costs.

Results of LCOE estimations obtained with method (A) results are illustrated in Figure 9. The estimates show rising total costs including the compensations and purchase costs. Distance between the total LCOE and the basic cost illustrates a measure of acceptance costs. Acceptance costs are a major cost element for an ambitious expansion of onshore wind capacity in Denmark, but a substantial expansion of wind can take place without exceeding the 4-5 EUR cents cost level.

* The authors are both with Systems Analysis Division, DTU Management Engineering, Technical University of Denmark 


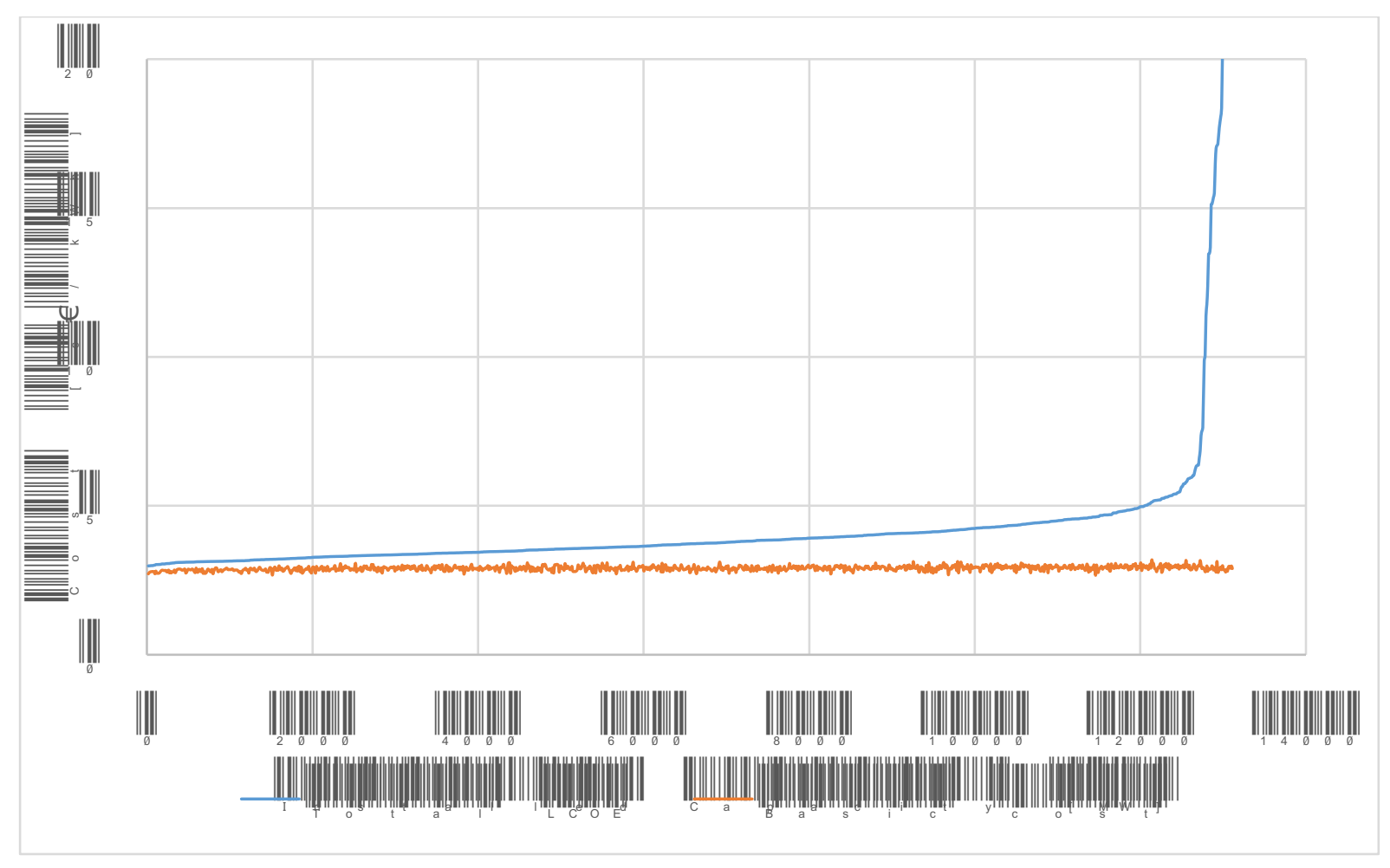

Figure 10: Onshore wind cost curve (LCOE) in Denmark including acceptance based on method $A$

For comparison, method (B) results are shown in Figure 10. The importance of the property purchase cost, only included in method (A), is evident, as total cost rises only gradually in method (B) reaching only $4 \mathrm{c} € / \mathrm{kWh}$ around the $12 \mathrm{GW}$ as compared to $5 \mathrm{c} € / \mathrm{kWh}$ in method (A). The cost of the approximately 3,400 dwellings purchased in method (A) is thus quite crucial for the resulting curve. In method (B) the basic value of the dwellings is the same, but the value loss is much lower as only $15 \%$ value loss is assumed for these according to the estimates in (Jensen et al., 2014) for distance to turbines of 200-600 $\mathrm{m}$ (maximum value in their Table 5). While this assumption may be too low, including full purchase costs for these dwellings (A) may also be seen as an upper bound for this cost component, since buildings may be resold and used for other purposes, such as farming, instead of being demolished.

* The authors are both with Systems Analysis Division, DTU Management Engineering, Technical University of Denmark 


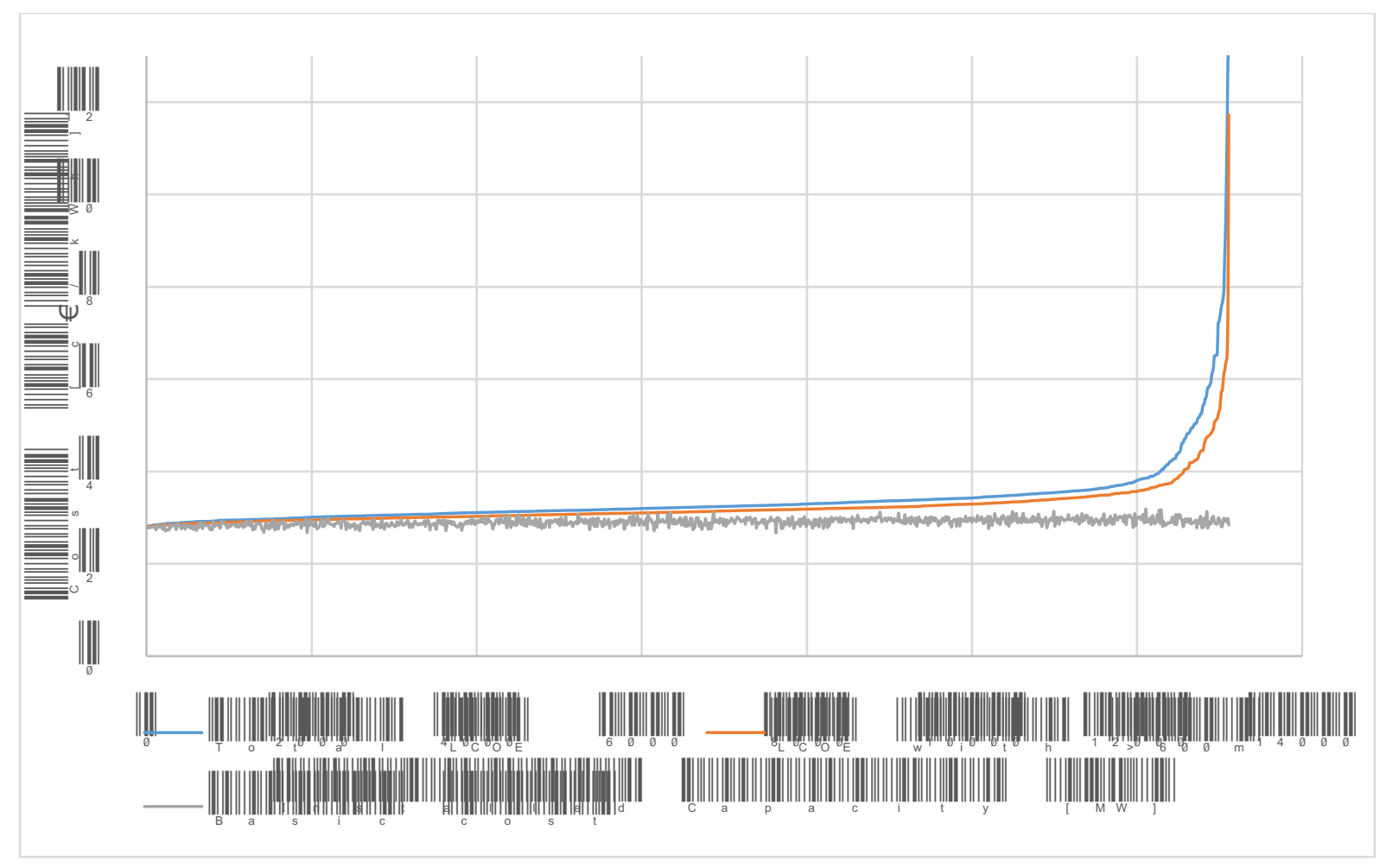

Figure 11: Onshore wind cost curve (LCOE) in Denmark including acceptance based on method $B$

Finally, for method (C) we create an LCOE cost curve for both high and low acceptance costs shown in Figure 11. We can see that the range of costs between the higher and lower estimate is quite extensive, mainly due to the high level of the upper estimate. This is expected, as the measure utilised for the high level of acceptance costs in method (C) is designed to be extensive and conservative, particularly in regards to considering every respondent in Denmark as being equally affected at every stage of development (due to the design of the survey, respondents are considering the expansion to affect them by siting wind turbines in their municipality or a neighbouring one). In regards to the lower LCOE curve, we can see that its levels are quite similar to the ones obtained with previous methods, with both curves from method (A) and method (B) placed above it. All three LCOE estimates are shown together in Figure 12, with a detail view in Figure 13.

* The authors are both with Systems Analysis Division, DTU Management Engineering, Technical University of Denmark 


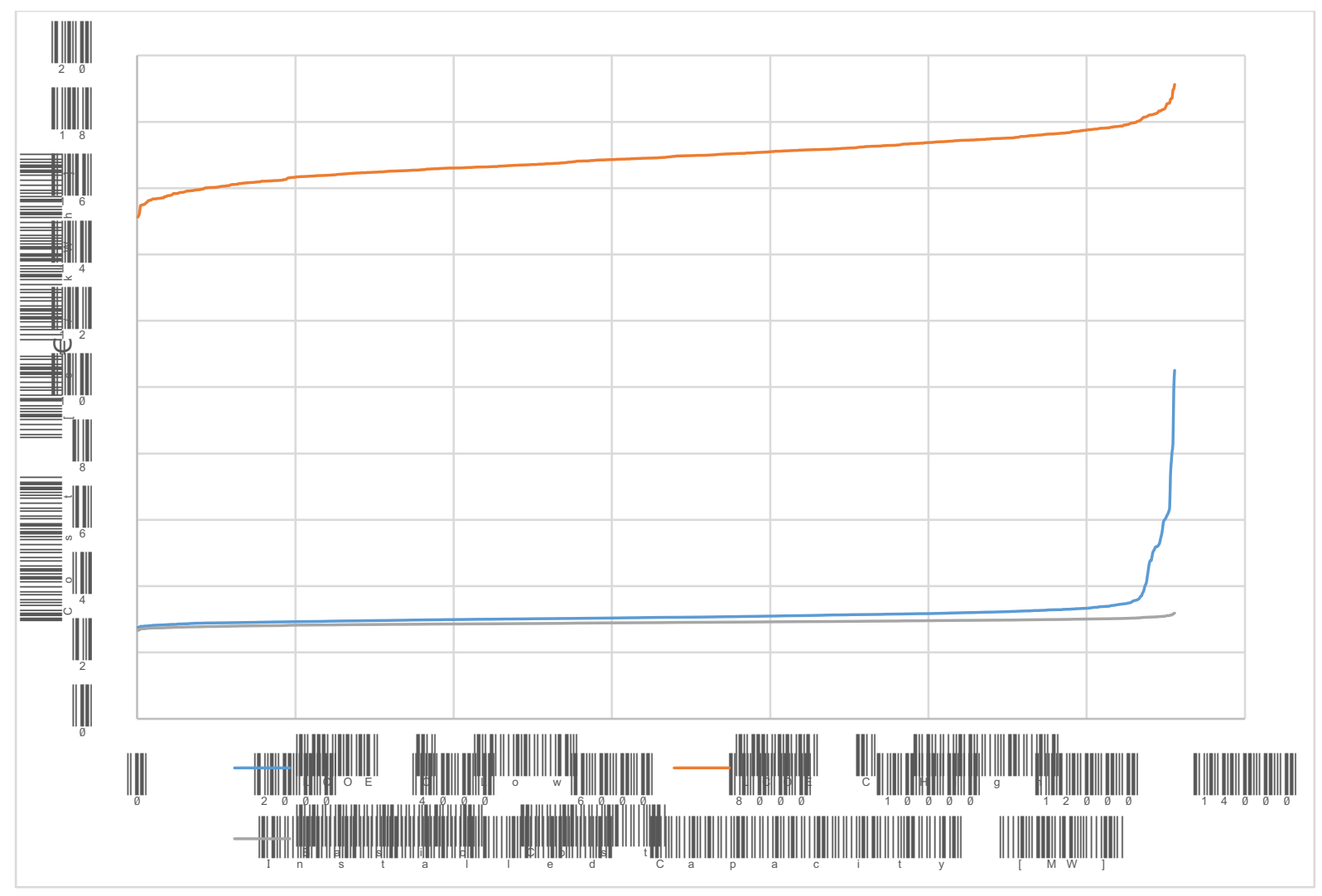

Figure 12: Onshore wind cost curve (LCOE) in Denmark including acceptance based on method $(C)$

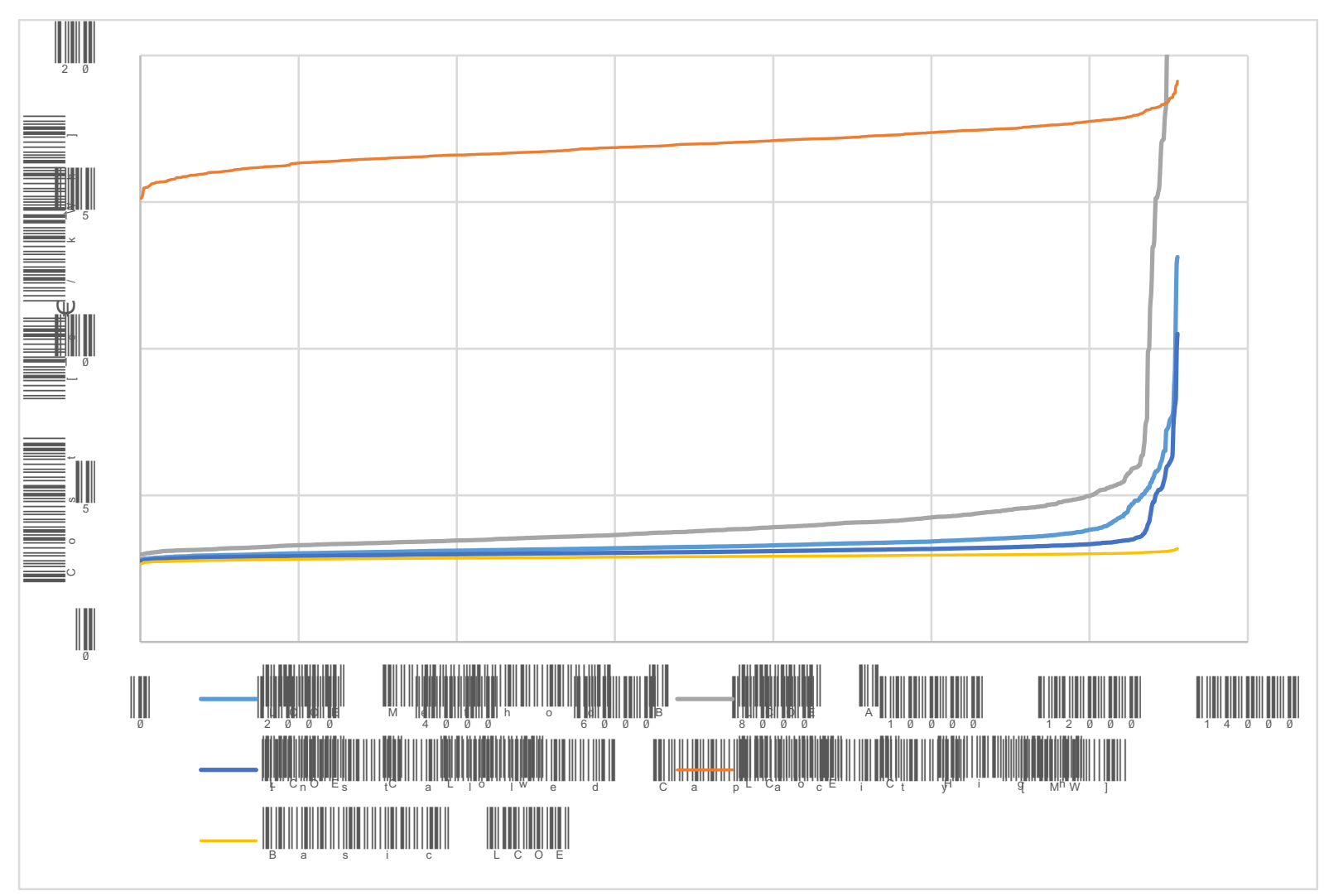

Figure 13: Onshore wind cost curves (LCOE) in Denmark including acceptance

* The authors are both with Systems Analysis Division, DTU Management Engineering, Technical University of Denmark 


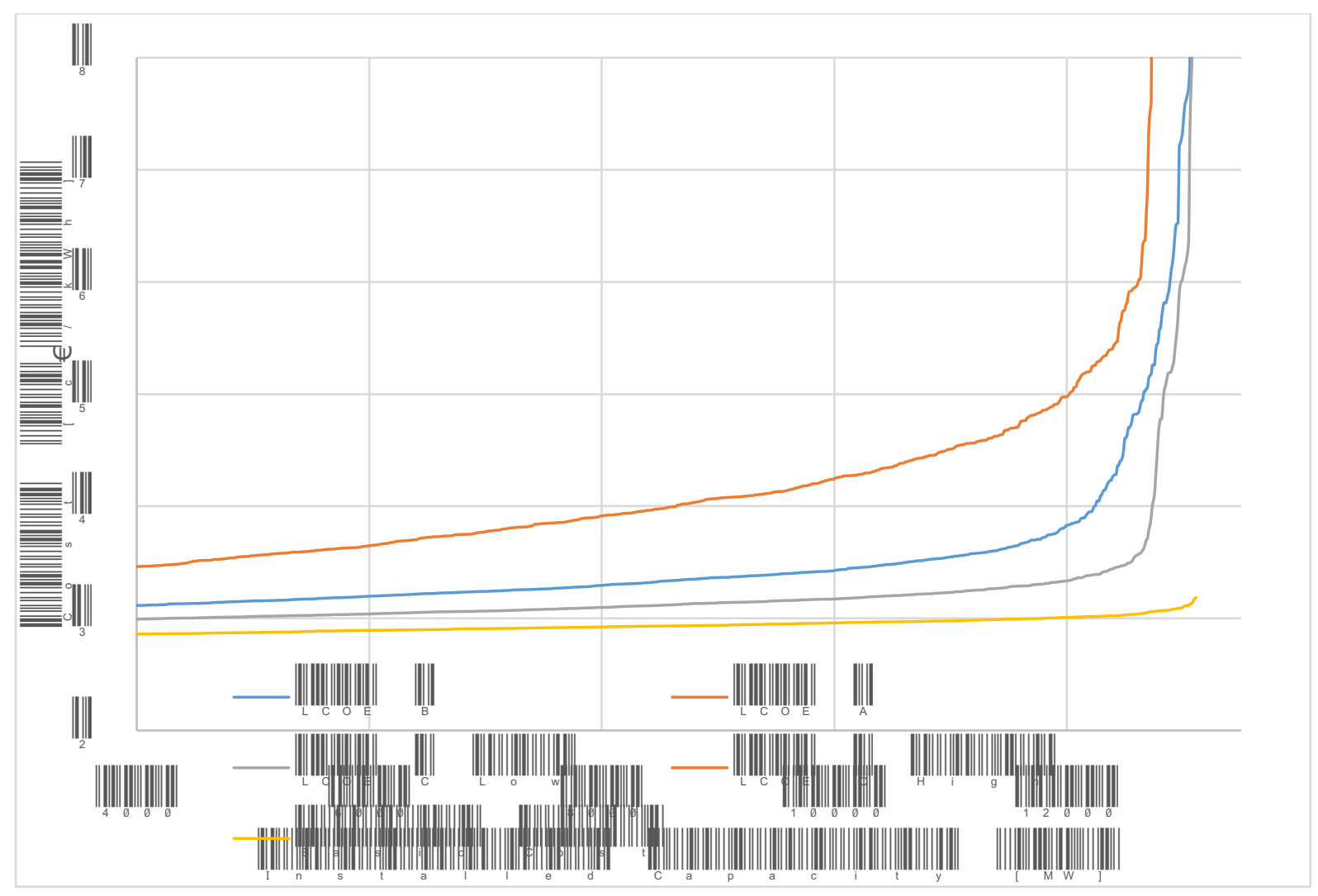

Figure 14: Onshore wind cost curves (LCOE) in Denmark including acceptance (Detail)

\section{Conclusion and policy implications of comparing onshore and offshore cost curves}

We have constructed cost curves onshore and offshore in Denmark with consistent assumptions on basic costs and added acceptance cost for the onshore part based on the three methods presented while assuming that there are no acceptance costs for the offshore wind potential. No acceptance costs for offshore is based on planned developments for the offshore cost curve being beyond the limits of visibility from the shore, eliminating acceptance costs from visual and sound disamenities. It is possible that there are still minor acceptance costs, regarding offshore wind farms as a technology per se, but they are not included in the present analysis.

* The authors are both with Systems Analysis Division, DTU Management Engineering, Technical University of Denmark 


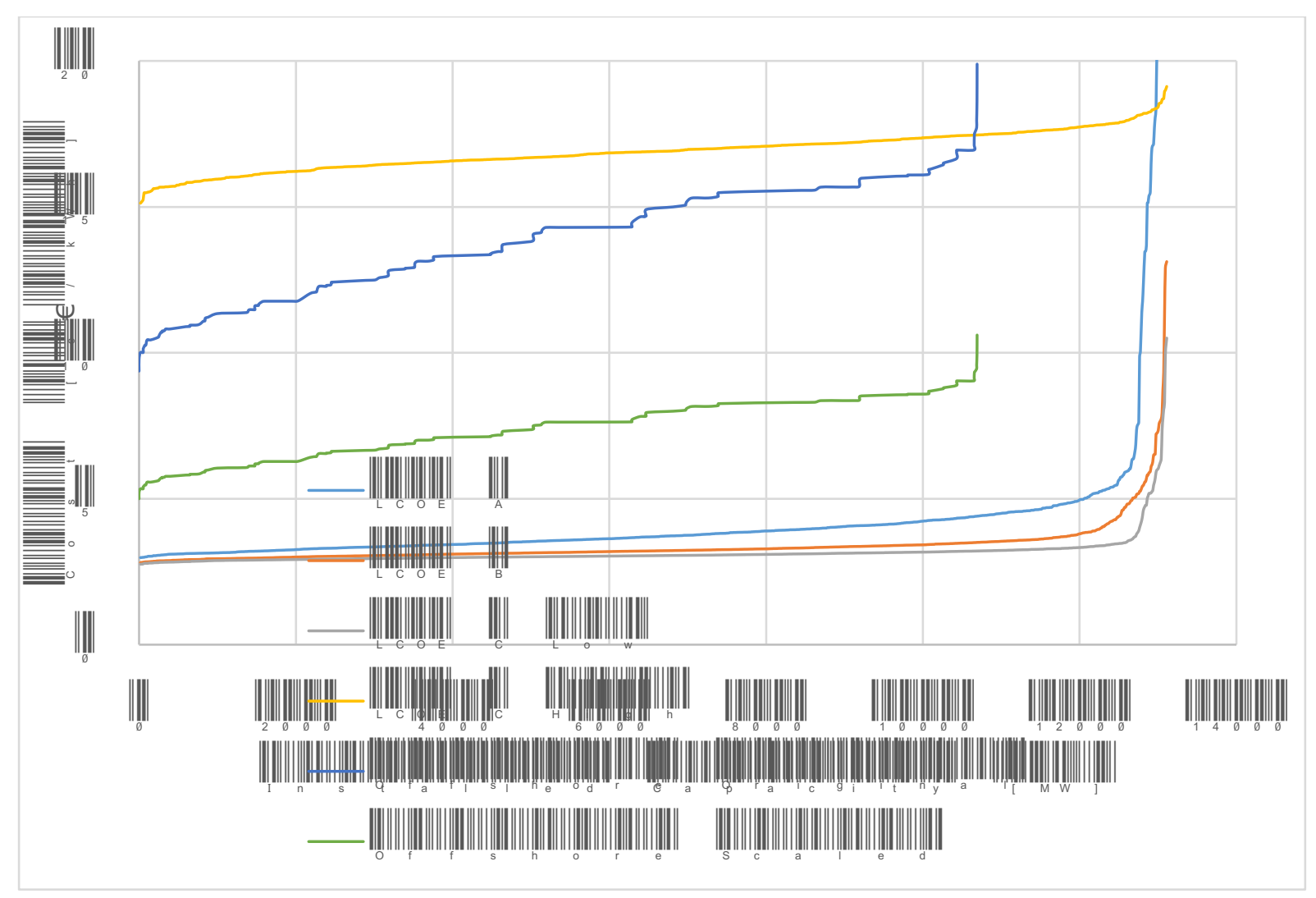

Figure 15: Onshore and offshore wind cost curves (LCOE) in Denmark including acceptance costs

When looking at cost curves that include acceptance costs for both onshore and offshore levels, as shown in Figure 14, we can see that the curves obtained by methods (A), (B) and (C) low begin at very similar levels, and evolve with different slopes. Nonetheless, they are packed in a relatively tight range with differences being noticeable only from a capacity of $4000 \mathrm{MW}$ and higher, point where the LCOE for method (A) increases faster than for method (B) and (C), due to the significant impact of increasing property purchase costs. The lower estimate obtained by method (C) provides an LCOE with lower local acceptance cost than the other two methods, whereas method (A) produces the highest ones, with differences from $0.2 \mathrm{c} € / \mathrm{kWh}$ at low capacities, up to $1.4 \mathrm{c} € / \mathrm{kWh}$ at around $11 \mathrm{GW}$ capacity, before the sharp increase on the latter stages of potential exploitation. On the other hand, the LCOE obtained by method (C) considering national level aggregation (that is, LCOE C High) has an extremely high level, comparable to the original offshore cost curve provided by (Beurskens \& Hekkenberg, 2011). Note that due to the nature of the aggregation and the design of the survey utilised, this acceptance cost level is expected to be high, and act as a measure of an upper bound, more than a precise cost level. Specifically, this method assumes a flat constant WTP based on the scenario shown on the survey (an expansion of $450 \mathrm{MW}$ of installed wind capacity) and not precise steps for the total $12 \mathrm{GW}$ potential considered here.

We can see that in general, the acceptance costs increase the total LCOE level for onshore wind energy. Nonetheless, both method (A) and (B) present cost estimates below the adjusted cost levels for offshore wind. Based on those figures up to $12 \mathrm{GW}$ of wind capacity, onshore wind presents lower cost levels than offshore wind. When we look at method (C), though, we can see that while the lower bound cost curve is quite similar to the levels obtained by the previous two methods, the upper bound creates a wide range for increased costs. While part of this variation is intrinsic to the error associated with the methodology used, another part of it is dependent on the extent of the population considered. It is important to note that this method considers acceptance costs not included in the previous two methods. Based on both the broad range between upper and lower bounds, as well as the existence of sources of acceptance cost not considered by methods (A) or (B), it is possible that the crossover point between offshore and onshore costs occurs at capacities lower than $12 \mathrm{GW}$.

* The authors are both with Systems Analysis Division, DTU Management Engineering, Technical University of Denmark 
Finally, LCOE levels for offshore wind are subject to high uncertainty, as evidenced by the significant differences between recent estimates and actual cost developments, as exemplified in Figure 5. As discussed previously, the LCOE of offshore wind energy has been reduced significantly in recent years, particularly compared to onshore, and if this trend were to continue the economic advantage of onshore versus offshore would be further reduced.

Danish energy policy has until today supported onshore and offshore wind development differently, with feed-in premiums onshore and tendered/auctioned offshore development with fixed amounts (TWh) supported by fixed feed-in tariffs (contract for differences). Apart from the support scheme differences also the resulting auction based level of support has been considerably higher for offshore wind development. Costs have come down for offshore, but still, it is likely that considerable savings can be achieved by developing more onshore capacity compared to offshore. This is as illustrated above even the case with the inclusion of additional acceptance costs for onshore development. The exact share of onshore to offshore wind that should be installed is uncertain and will depend on further cost improvements of offshore development, as well as the definition of the population range to be considered as affected, and therefore included in the aggregation.

It is of relevance, then, to further study acceptance costs at a scope more inclusive than the local one, to determine the share of onshore to offshore wind expansion. This would require the design of stated preference studies that look at realistic nation-wide scenarios of wind expansion that is reflected clearly in the survey design. Despite the approximations in the present study, results indicate that there is still a significant advantage of onshore wind at lower expansion capacities, as well as the possibility of repowering existing wind farms with larger and more efficient wind turbines which, due to the reduced number, may lower acceptance costs. This presents an argument towards equivalence in support schemes for onshore and offshore wind development.

This paper shows three different approaches for calculating acceptance costs for onshore wind energy in Denmark and using these levels to create a cost curve for the expansion of wind energy capacity. Afterwards, we compare these cost curves for onshore wind energy to cost levels for offshore wind energy in Denmark.

We find that method (A), utilising data from the compensation scheme, green fund allocations, offering of $20 \%$ of the project locally, and required property purchases; indicates that for most of the available expansion capacity, onshore wind is cheaper than offshore wind even when considering acceptance costs. With the sharp increase of onshore costs at high levels of capacity (above $12.5 \mathrm{GW}$ ) associated with the necessity of buying more expensive, properties, total costs for onshore may exceed offshore cost levels. The acceptance costs with method (A) are only local, thus largely restricted to the population living in the specific areas (less than $10 \mathrm{~km} 2$ ) where wind turbines will be installed. When considering the large nation-wide expansion of onshore wind, there will be significant amounts of people affected, but only a few people for each turbine.

Also from a local acceptance costs perspective, method (B), based on a revealed preference study (Jensen et al., 2014), presents similar local acceptance cost estimates to method (A), when applied to an equivalent amount of households, although slightly lower. From this estimated curve, similar conclusions are drawn: onshore wind has an economic advantage over offshore wind for most of the wind capacity expansion range studied.

Utilising method (C), we obtain estimates for acceptance costs both at a local scope and a national scope, to be used as bounds for acceptance costs that will vary depending on the level of aggregation of the measure. The lower estimate (local perspective as defined by method (A)), has cost estimates that are slightly lower, but similar to the costs obtained by methods (A) and (B); and with similar conclusions. The higher estimate, on the other hand, is a cost curve at an extremely high level, much higher than the adjusted offshore cost curve utilised in this study, which was expected due to the overestimating nature of the aggregation done. Based on the dimension of the range obtained, the fact that methods (A) and (B) are, while more accurate, ignoring the willingness to pay of the broader population to avoid turbines onshore; and the recent downwards development of offshore cost, it is much harder to conclude with

* The authors are both with Systems Analysis Division, DTU Management Engineering, Technical University of Denmark 
certainty the absolute cost advantage of onshore wind versus offshore wind, as well as the specific crossover point. The main part of the onshore capacity available will be cheaper considering only the local acceptance costs but depending on how much of the estimated willingness to pay from the larger Danish population is included, larger parts of the onshore potential will be at cost levels that are matched by offshore potential.

\section{Acknowledgements}

The authors much appreciate the access provided by Energinet.dk to data used in the Energinet.dk study (2015). Special thanks to Loui Algren for his valuable comments. The authors also want to thank two anonymous reviewers for their comments and suggestions. The use of data, results and conclusions are the sole responsibility of the authors. This work was funded by Project 1305-00021B under the Danish Council for Strategic Research (Wind 2050).

\section{References}

Balyk, O., Andersen, K. S., Dockweiler, S., Gargiulo, M., Karlsson, K., Næraa, R., ... Venturini, G. (n.d.). TIMESDK: Technology-Rich Multi-Sectoral Optimisation Model of the Danish Energy System (Energy Strategy Reviews [Under Review]).

Beurskens, L. W. M., \& Hekkenberg, M. (2011). Renewable Energy Projections as Published in the National Renewable Energy Action Plans of the European Member States. qualenergia.it.

Danish Energy Agency. (n.d.). Stamdataregister for vindkraftanlæg [Master data register of wind turbines].

Danish Energy Agency. (2015). Eksisterende havvindmølleparker og aktuelle projekter.

Danish Energy Agency. (2017). Master Data Register of Wind Turbines.

Danish Energy Agency, \& Energinet.dk. (2013). New Offshore Wind Tenders in Denmark.

Danish Ministry of Taxation. (2016). Duties and subsidies analysis Report 6: Future support for onshore wind (In Danish) (Vol. May).

DECC (Department of Energy \& Climate Change). (2013). Electricity Generation Costs. https://doi.org/267393///1/125 May 2010

Energinet.dk. (2015a). An analysis of the potential for landbased wind in Denmark up to 2030 (In Danish).

Energinet.dk. (2016). Analyse: Nedtagning af gamle landmøller.

Energinet.dk, \& Danish Energy Agency. (2017). Technology Data for Energy Plants August 2016: Update June, October and November 2017.

EWEA. (2009). The economics of wind energy. Renewable and Sustainable Energy Reviews (Vol. 13). https://doi.org/10.1016/j.rser.2008.09.004

Fichtner/prognos. (2013). Cost Reduction Potentials of Offshore Wind Power in Germany.

Forcherio, G. T. (2014). LCOE Calculator Model. https://doi.org/10.4231/D3XG9FB9Z

Fraunhofer ISE. (2013). Levelized Cost of Electricity Renewable Energy Technology.

Hanley, N., Wright, R. E. R. E., \& Adamowicz, V. (1998). Using choice experiments to value the environment: design issues, current experience, and future prospects. Environmental and Resource Economics, 11(3-4), 413-428. https://doi.org/10.1023/A:1008287310583

Heptonstall, P., Gross, R., Greenacre, P., \& Cockerill, T. (2012). The cost of offshore wind: Understanding the past and projecting the future. Energy Policy, 41, 815-821. https://doi.org/10.1016/j.enpol.2011.11.050

* The authors are both with Systems Analysis Division, DTU Management Engineering, Technical University of Denmark 
Hevia-Koch, P., \& Ladenburg, J. (2016). Estimating Preferences for Wind Turbine Locations - A Critical Review of Visualisation Approaches. SSRN Electronic Journal. https://doi.org/10.2139/ssrn.2848529

Hevia-Koch, P., Ladenburg, J., \& Petrovic, S. (2018). The offshore-onshore conundrum: preferences for wind energy considering spatial data in Denmark.

International Renewable Energy Agency. (2012). Wind Power Cost Analysis (Vol. 1).

IRENA. (2012). Renewable Energy Technologies: Cost Analysis Series (Vol. 1).

Jensen, C. U., Panduro, T. E., \& Lundhede, T. H. (2014). The Vindication of Don Quixote: The Impact of Noise and Visual Pollution from Wind Turbines. Land Economics, 90(4), 668-682. https://doi.org/10.3368/le.90.4.668

Kitzing, L., \& Morthorst, P.-E. (2015). Trends in offshore wind economics - the past and the future. Proceedings - 14th Wind Integration Workshop.

Krueger, A., Parsons, G., \& Firestone, J. (2011). Valuing the visual disamenity of offshore wind power projects at varying distances from the shore: An application on the Delaware shoreline. Land Economics, 87(2), 268-283.

Millborrow, D. (2016, January). Global costs analysis -- the year offshore wind costs fell. Wind Power Monthly.

Mone, C., Hand, M., Maples, B., \& Smith, A. (2015). 2013 Cost of Wind Energy Review. Golden, CO.

Morthorst, P. E., \& Kitzing, L. (2016). Economics of building and operating offshore wind farms. In Offshore wind farms: Technologies, Design and Operation (pp. 9-28). Woodhead Publishing Series in Energy.

Naturstyrelsen. (2014). Status for municipality planning of future onshore wind in Denmark (In Danish).

Prässler, T., \& Schaechtele, J. (2012). Comparison of the financial attractiveness among prospective offshore wind parks in selected European countries. Energy Policy, 45, 86-101. https://doi.org/10.1016/j.enpol.2012.01.062

The Crown Estate. (2012). Offshore Wind Cost Reduction Pathways Study.

The Danish Wind Turbine Owners' Association. (2014). Når all-inclusive service alligevel ikke dækker alt. Naturlig Energi, Nov.

TKI Wind op Zee. (2015). TKI Wind op Zee Cost reduction options for Offshore wind in the Netherlands FID 2010-2020.

Voormolen, J. A., Junginger, H. M., \& van Sark, W. G. J. H. M. (2015). Unravelling historical cost developments of offshore wind energy in Europe. Energy Policy, 88, 435-444. https://doi.org/10.1016/j.enpol.2015.10.047

Wiser, R., Jenni, K., Seel, J., Baker, E., Hand, M., Lantz, E., \& Smith, A. (2016). Forecasting Wind Energy Costs \& Cost Drivers : The Views of the World's Leading Experts. IEA Wind Task 26.

Wiser, R., Yang, Z., Hand, M., Hohmeyer, O., Infield, D., Jensen, P. H., ... Zervos, A. (2011). Wind Energy. IPCC Special Report on Renewable Energy Sources and Climate Change Mitigation, 535-608.

* The authors are both with Systems Analysis Division, DTU Management Engineering, Technical University of Denmark 


\section{Appendix}

Table 4: Sample Characteristics and National Sample

\begin{tabular}{|c|c|c|c|c|c|}
\hline Variable $(\mathrm{N}=1,754)$ & Mean/share (\%) & $\begin{array}{l}\text { Standard } \\
\text { Deviation. }\end{array}$ & Min & Max & $\begin{array}{r}\text { Statistics } \\
\text { Denmark }{ }^{\text {a, b }} \\
\end{array}$ \\
\hline Age & 45.1 & 12.6 & 20 & 67 & 43.8 \\
\hline Male & $49.6 \%$ & & & & \\
\hline \multicolumn{6}{|l|}{ Education } \\
\hline Primary school & $5.4 \%$ & & & & $24.9 \%$ \\
\hline High school & $11.1 \%$ & & & & $9.0 \%$ \\
\hline Vocational & $18.4 \%$ & & & & $36.8 \%$ \\
\hline Short Secondary & $10.0 \%$ & & & & $4.5 \%$ \\
\hline Bachelor & $34.2 \%$ & & & & $17.1 \%$ \\
\hline Master or $\mathrm{PhD}$ & $20.2 \%$ & & & & $8.1 \%$ \\
\hline \multicolumn{6}{|l|}{ Household income per year (€) (HHI) } \\
\hline $\mathrm{HHI}<26,667$ & $14.0 \%$ & & & & $22.6 \%$ \\
\hline $26,666>\mathrm{HHI}<40,000$ & $9.2 \%$ & & & & $19.8 \%$ \\
\hline 39,999> $>$ HHI $<53,333$ & $14.3 \%$ & & & & $14.3 \%$ \\
\hline $53,332>\mathrm{HHI}<66,667$ & $11.7 \%$ & & & & $9.5 \%$ \\
\hline $66,666>\mathrm{HHI}<80,000$ & $13.8 \%$ & & & & $7.5 \%$ \\
\hline 79,999>HHI<93,333 & $12.3 \%$ & & & & $7.2 \%$ \\
\hline 93,332>HHI & $24.6 \%$ & & & & $19.2 \%$ \\
\hline $\begin{array}{l}\text { Knowledge of wind turbines } \\
\text { development plans in municipality } \\
\text { Number of turbines visible from } \\
\text { permanent or summer residence }\end{array}$ & $14.8 \%$ & & & & \\
\hline 0 turbines & $86.5 \%$ & & & & $74.8 \% / 76.0 \%$ \\
\hline 1 turbine & $1.9 \%$ & & & & \\
\hline 2-3 turbines & $5.4 \%$ & & & & \\
\hline 4-5 turbines & $3.2 \%$ & & & & \\
\hline 6-10 turbines & $1.9 \%$ & & & & \\
\hline$>10$ turbines & $1.0 \%$ & & & & \\
\hline Distance to the beach $(\mathrm{km})$ & 7.8 & 8.4 & 0.016 & 52.3 & \\
\hline $\begin{array}{l}\text { Distance to nearest potential offshore } \\
\text { wind farm }(\mathrm{km}) \\
\text { Density of onshore turbines in postal } \\
\text { code area }\end{array}$ & 108.8 & 40.6 & 7.7 & 206.3 & \\
\hline No turbines in postal code area & $43.2 \%$ & & & & \\
\hline $\begin{array}{l}\text { Density of small turbines in postal } \\
\text { code area (Number/km2) }\end{array}$ & 0.048 & 0.071 & 0 & 0.578 & \\
\hline $\begin{array}{l}\text { Density of medium turbines in postal } \\
\text { code area (Number } / \mathrm{km} 2 \text { ) }\end{array}$ & 0.0063 & 0.017 & 0 & 0.2158 & \\
\hline $\begin{array}{l}\text { Density of large turbines in postal code } \\
\text { area (Number/km2) }\end{array}$ & 0.0030 & 0.016 & 0 & 0.2346 & \\
\hline
\end{tabular}

Notes: a) Statistics Denmark, age of population in age group 20-67 FOLK1A, ${ }^{\text {b) }}$ Statistics Denmark highest completed education HFUDD10 age group 20-69, c) Statistics Denmark, family income level INDKF122

* The authors are both with Systems Analysis Division, DTU Management Engineering, Technical University of Denmark 
Table 5: Estimated Willingness-To-Pay

\begin{tabular}{lc}
\hline & $\begin{array}{c}\text { Main effect } \\
\text { model }\end{array}$ \\
\hline MW3 & $327.0^{* * *}$ \\
& {$[50.22]$} \\
MW15 & $331.0^{* * *}$ \\
& {$[65.82]$} \\
dist1000 & $306.6^{* * *}$ \\
dist1000Xmw & {$[53.61]$} \\
3 & $-652.7^{* * *}$ \\
dist1000Xmw & {$[90.17]$} \\
15 & $-625.5^{* * *}$ \\
dist1000mw3 & {$[88.22]$} \\
dist1000mw1 & -19.11 \\
5 & {$[53.76]$} \\
bebor100 & 12.09 \\
bebor11100 & {$[55.66]$} \\
jammer & $-185.7^{* *}$ \\
asc & {$[61.54]$} \\
dist50 & -30.04 \\
moen & {$[39.79]$} \\
vester & $612.5^{* * *}$ \\
& {$[80.78]$} \\
& $89.13^{+}$ \\
& {$[53.76]$} \\
& $370.8^{* * *}$ \\
& {$[69.39]$} \\
& $331.0^{* * *}$ \\
& {$[61.05]$} \\
& 15.77 \\
& {$[81.97]$} \\
& $129.4^{*}$ \\
& {$[54.38]$} \\
& -42.23 \\
& {$[60.03]$} \\
& $-295.0^{* *}$ \\
& \\
dist18 &
\end{tabular}

* The authors are both with Systems Analysis Division, DTU Management Engineering, Technical University of Denmark 